\title{
Molecular dynamics simulation of water-based fracturing fluids in kaolinite slit pores
}

Konstantinos D. Papavasileiou, ${ }^{1}$ Vasileios K. Michalis, ${ }^{1}$ Loukas D. Peristeras, ${ }^{1}$ Manolis Vasileiadis, ${ }^{1}$ Alberto Striolo, ${ }^{2}$ and Ioannis G. Economou ${ }^{1,3, *}$

${ }^{1}$ National Center for Scientific Research "Demokritos", Institute of Nanoscience and Nanotechnology, Molecular Thermodynamics and Modelling of Materials Laboratory, GR-15310 Aghia Paraskevi Attikis, Greece

${ }^{2}$ University College London, Department of Chemical Engineering, WC1E 7JE, London, United Kingdom

${ }^{3}$ Texas A\&M University at Qatar, Chemical Engineering Program, Education City, PO Box 23874, Doha, Qatar

*To whom correspondence should be addressed

IGE: ioannis.economou@ qatar.tamu.edu

Submitted for publication to Journal of Physical Chemistry C

April 2018 


\begin{abstract}
The adsorption behavior inside kaolinite mesopores of aqueous solutions of various salts and additives is investigated using Molecular Dynamics simulations. In particular, we examine the various combinations of water + salt, water + additive, and water + salt + additive mixtures, where the salts examined are $\mathrm{NaCl}, \mathrm{CsCl}, \mathrm{SrCl}_{2}$ and $\mathrm{RaCl}_{2}$ and the additives are methanol and citric acid. Citric acid is modeled in two forms, namely fully protonated $\left(\mathrm{H}_{3} \mathrm{~A}\right)$ and fully deprotonated $\left(\mathrm{A}^{3-}\right)$, the latter being prevalent in neutral $\mathrm{pH}$ conditions, in accordance with the kaolinite structure employed. The force fields used for the individual system components include CLAYFF for the kaolinite mesopores, SPC/E for water, parameters optimized for the SPC/E water model based on hydration free energies (HFE) for ions and general Amber force field (GAFF) for the additives. The spatial distributions along the kaolinite pore are delineated and reveal the preferential adsorption behavior of the various species with respect to the gibbsite and siloxane surface, as well as the effect on this behavior of the interactions between the various species. Furthermore, we examine the hydrogen bonds formed between the kaolinite surfaces and water molecules as well as the additives. For the case of citric acid, which tends to aggregate, a cluster analysis is also carried out, in order to examine the effect of the various ions on the cluster formation. Finally, through the calculation of lateral diffusion coefficients and mean residence times, we provide insights on the mobility of the various species inside the kaolinite mesopores.
\end{abstract}

Keywords: kaolinite, fracturing fluid, citric acid, methanol, molecular dynamics, NORM 


\section{Introduction}

The steady decline in conventional fuel resources as well as their large environmental footprint has led to the quest of alternative fuel sources over the last few decades. The delicate balance between the need to satisfy the ever-increasing industrial and consumer energy demands and the need to lower harmful emissions has led to the exploration of unconventional hydrocarbon repositories. In this regard, shale gas, which is natural gas hosted in shale formations, has revolutionized the industrial sector in North America. ${ }^{1}$ Shale formations are chemically and structurally diverse, containing kerogen, clay, calcite and quartz, in compositions that vary substantially from region to region. ${ }^{2}$ Clay minerals are a major constituent, characterized by an extensive network of micropores and mesopores. ${ }^{3}$ Among these hydrous aluminosilicates, kaolinite is one of the most abundant on Earth ${ }^{4}$ and is commonly encountered in shales. ${ }^{5}$

Kaolinite $\left(\mathrm{Al}_{2} \mathrm{Si}_{2} \mathrm{O}_{5}(\mathrm{OH})_{4}\right)$ is a 1:1-type clay mineral with alternating layers, each composed of a single tetrahedral silicon-oxygen (siloxane) and an octahedral aluminum-oxygen (gibbsite) sheet. ${ }^{6}$ Sheets are interconnected by bridging oxygen atoms and each kaolinite layer has basal surfaces of different termination. ${ }^{6}$ The gibbsite hydroxyl basal surface forms hydrogen bonds (HB) with the siloxane sheet oxygens, which results in a tightly packed triclinic unit cell structure. ${ }^{7}$ This gives rise to non-swelling layers that are not easily broken down or separated, compared to other clays. ${ }^{8}$ Isomorphous substitution is rather limited and kaolinite is typically a neutral clay material. ${ }^{6,-10}$ Deviations from neutrality are possible however and have been reported in literature in cases of either substitution of octahedral $\mathrm{Al}^{3+}$ by metals such as $\mathrm{Fe}^{2+}, \mathrm{Cu}^{2+}$ and $\mathrm{Ti}^{4+6,9,11-13}$ or edge ruptures that result to kaolinite carrying a small negative charge usually balanced by cation adsorption. ${ }^{10}$ Under neutral $\mathrm{pH}$ conditions $(6<\mathrm{pH}<8)$, the gibbsite basal surface is fully 
hydroxylated (i.e. $\mathrm{AlOH}$ ) and no variations are present on the siloxane surface (i.e. $\mathrm{SiO}_{2}$ for $\mathrm{pH}>$ 4)..$^{14}$

Kaolinite, as well as other clay minerals, has attracted a lot of attention for their basal surface and edge adsorption potential, particularly in terms of controlling the fate of chemical and environmental waste as scavengers. ${ }^{9,}{ }^{15}$ Depending on their chemical nature, contaminants interact with clays through ion exchange, coordination, ion-dipole, hydrogen-bonding (HB) and van der Waals interactions, leading to their immobilization on their surface. ${ }^{9}$

Kaolinite has attracted a lot of research interest due to its importance in the extraction of gas and oil trapped in shale reservoirs, which is achieved by hydraulic fracturing, an established and extensively used technique for well stimulation. ${ }^{16}$ Fracturing fluids are categorized depending on their base, ${ }^{17}$ i.e. their primary constituent. Water-based fluids are the most common ones and contain several chemicals, although at low concentrations. ${ }^{18}$ According to the U.S. House Energy and Commerce Committee "Chemicals used in hydraulic fracturing" report, methanol is the most widely used additive ${ }^{19-20}$ in small fractions of the total fluid volume, ${ }^{17}$ playing a diverse role in corrosion or scale inhibition, friction reduction, formation water flowback enhancement, and fracking fluid flowback enhancement. ${ }^{19}, 21-22$ Another additive is citric acid, ${ }^{20,23}$ which is used primarily to prevent the release of ferric iron, a problematic factor in fracturing. ${ }^{24-27}$ Apart from the presence of chemicals, fracturing fluids returning to the surface have been found to contain elevated levels of strontium $\left(\mathrm{Sr}^{2+}\right)$, sodium $\left(\mathrm{Na}^{+}\right)$and chloride $\left(\mathrm{Cl}^{-}\right)$ions, as well as naturally occurring radioactive materials (NORM) such as radium $\left(\mathrm{Ra}^{2+}\right)$ isotopes. ${ }^{28-30}$

In order to gain a better understanding of the fundamental processes occurring during fracturing, one needs to closely examine the physical properties of fracturing fluids in shale, ${ }^{2}$ particularly rock-fluid interactions and fluid transport mechanisms of environmentally relevant 
compounds at the nanometer scale. ${ }^{31-32}$ Rationalizing these processes in clays such as kaolinite will aid in predicting the fate of substances with potential environmental impact during shale gas exploitation, limit the amount of NORM released from shale without compromising gas and oil extraction and fracturing fluid formulation. Given the experimental difficulties in probing the relevant mechanisms at the aforementioned scale, atomistic simulation and in particular molecular dynamics (MD) can play a central role in enhancing our understanding of the relevant phenomena, due to its intrinsic capability of providing information at the molecular level. ${ }^{33-34}$

Several MD studies of water solutions containing small organic molecules, ions or both on kaolinite surfaces have been reported in literature. One of the earliest modeling attempts of the adsorption of organic molecules on a kaolinite and pyrophyllite mineral/aqueous solution interface was by Teppen et al. ${ }^{35}$ who studied trichloroethene, $\mathrm{C}_{2} \mathrm{HCl}_{3}$, as a typical chlorinated hydrocarbon pollutant. Their calculations showed that water outcompetes $\mathrm{C}_{2} \mathrm{HCl}_{3}$ for the clay surfaces examined and its interaction with the surface depends on the water load. Warne et al. ${ }^{36}$ performed MD simulations of aqueous kaolinite and amorphous silica surface systems, showing that the selfdiffusion coefficient of surface water exhibits a pronounced decrease. Vasconcelos et al. ${ }^{15}$ performed MD simulations to investigate ion adsorption of aqueous solutions of $\mathrm{CsCl}, \mathrm{NaCl}$, $\mathrm{CdCl}_{2}$, and $\mathrm{PbCl}_{2}$ on basal surfaces. Their results showed that $\mathrm{Cs}^{+}$and $\mathrm{Cl}^{-}$adsorb on the siloxane and gibbsite surfaces, respectively, forming strong inner-sphere complexes, while $\mathrm{Na}^{+}, \mathrm{Cd}^{2+}$ and $\mathrm{Pb}^{2+}$ form outer-sphere complexes on the siloxane surface. Šolc et al. ${ }^{37}$ investigated with MD simulations the wettability of water droplets on the basal kaolinite surfaces, using three different water models (SPC, SPC/E, and TIP4P). Their results showed that the octahedral surface formed from surface hydroxyl groups is fully hydrophilic, whereas on siloxane the interactions with the basal oxygens are much weaker, with water hydrogen bonds formed inside the droplet being 
stronger compared to the ones formed with the siloxane surface. Greathouse et al. ${ }^{38}$ performed simulations, using a combination of quantum (density functional theory) and classical molecular simulation methods, in order to study the adsorption of methylene blue organic dye on kaolinite. Their results showed that the dye, either in the neutral or charged state, preferred adsorption on the hydrophobic siloxane surface. ${ }^{38} \mathrm{Li}$ et al. performed a systematic investigation on the adsorption of $\mathrm{Na}^{+}$and $\mathrm{Pb}^{2+}$ ions on both regular and defective kaolinite surfaces, showing that defect presence alters affinity and complexation mode from outer to inner-sphere, particularly for $\mathrm{Na}^{+} .{ }^{39}$ The same authors extended their study on $\mathrm{OH}^{-}, \mathrm{F}^{-}, \mathrm{Cl}^{-}$and $\mathrm{I}^{-}$anion adsorption on kaolinite surfaces bearing isomorphous substitutions, showing that anions construct H-bonds on the hydroxylated surface forming stable inner-sphere complexes, and also have a considerable impact on the adsorption behavior and stability of metal ions. ${ }^{40}$

Underwood et al. ${ }^{14}$ performed MD simulations to understand the interactions of $n$-decane, decanoic acid and decanamine with kaolinite surfaces, by also accounting for $\mathrm{pH}$ effects. Their results showed that $n$-decane and decanoic acid tend to form droplets at the siloxane surface, while decanamine readily adsorbs on both. However, $\mathrm{pH}$ effects largely control affinity towards either surface, with decanoate anions readily adsorbing on the hydroxyl surface through an anion exchange, whereas protonated decanamine adsorbed on the hydroxyl surface via anion bridges. Additionally, $\mathrm{Na}^{+}$ions were found to adsorb on both surfaces, while $\mathrm{Cl}^{-}$ions only adsorbed to the hydroxyl surface. ${ }^{14}$ Zhang et al. ${ }^{41}$ performed non-equilibrium MD simulations of four typical clay mineral slit pores (pyrophyllite, montmorillonite, illite, and kaolinite) and confined water/ $n$ decane/salts fluids. Their results highlighted that for kaolinite, the presence of salts makes the siloxane surface completely water-wet, whereas it is partially alkane-wet in the absence of salts. In general, the salt ions adsorbed onto clay surfaces promote the surface hydrophilicity. Also, basal 
surfaces remarkably restrain the movement of the water confined in mesopores, while the organic molecules (n-decane) aggregate to form clusters. ${ }^{41}$ Lastly, Greathouse et $a l .{ }^{42}$ studied the adsorption of aqueous crude oil components such as $n$-hexane, cyclohexane, toluene and the decahydro-2-naphthoic acid (DHNA) resin, on several clay mineral basal surfaces, including kaolinite. All organic molecules showed preference for adsorption on the siloxane side, with the exception of the anionic resin form $\left(\mathrm{DHNA}^{-}\right)$, which showed significant adsorption on the hydroxylated kaolinite surface, forming bridged cation complexes. ${ }^{42}$

The objective of this work is to study the properties of model water-based fracturing fluids in narrow slit pores representative of the typical ones found within clay formations/kaolinite mesopores, by means of extensive MD simulations. We quantify the preferential distribution and adsorption behavior of fluid components (e.g. water, methanol, citric acid, salts and simple models representing NORM) through spatial distributions along the kaolinite pore and we study the hydrogen bonds formed between the kaolinite surfaces and water molecules as well as the additives. Finally, we provide information on the mobility of the various species within the pore, through the calculation of lateral diffusion coefficients and mean residence times.

\section{Computational methods}

\subsection{Models}

A supercell kaolinite structure was obtained by merging 324 unit cells with parameters of $a=$ $0.51535 \mathrm{~nm}, b=0.89419 \mathrm{~nm}, c=0.73906 \mathrm{~nm}, \alpha=91.926^{\circ}, \beta=105.046^{\circ}, \gamma=89.797^{\circ} 7(9 \times 9 \times 4$ respectively along $a, b$, and $c$, respectively). This gave rise to a total of four kaolinite layers, i.e. eight siloxane and gibbsite sheets. Following the protocol of previous simulation studies, the 
triclinic supercell produced was in turn transformed to orthorhombic. ${ }^{15,40-41}$ These four kaolinite layers were then separated by introducing a $4 \mathrm{~nm}$ vacuum layer between the hydroxyl and siloxane basal surfaces, which is representative of the mesopore sizes encountered in shales and mudstones. ${ }^{41}$ The generation of the kaolinite slit pore system was performed by means of the Crystal Builder module integrated in Scienomics MAPS software package (Figure 1). ${ }^{43}$ Kaolinite slit pore was modelled by means of the CLAYFF force field ${ }^{44}$ which has proven particularly successful in studies of hydrated mineral systems and their interfaces at ambient conditions. ${ }^{15,40-}$ $41,45-46$

The kaolinite slit pore was then filled with water-based fracturing fluids, in concentrations satisfying the condition of maintaining a total density of $1.0 \mathrm{~g} \mathrm{~cm}^{-3}$. For the representation of water molecules the SPC/E ${ }^{47}$ model was employed. The SPC/E force field assumes a single LJ site on the oxygen atom and three charges on oxygen and hydrogen atoms, respectively, while bond lengths and bond angles are kept fixed. The SPC/E model, was selected for the present study, as it is suitable for use in combination with CLAYFF. ${ }^{48}$

Methanol and citric acid structures were initially optimized in the gas phase at the B3LYP/6-31G* level of theory, ${ }^{49-51}$ by means of the Gaussian $09^{52}$ suite of programs. As far as citric acid is concerned, given that kaolinite is considered under neutral $\mathrm{pH}$ conditions (i.e. gibbsite coverage with $\mathrm{AlOH}$ groups only and $\mathrm{SiO}_{2}$ coordinated siloxane surface), it was studied at its predominantly encountered fully deprotonated state. ${ }^{53}$ For comparison, the fully protonated citric acid was also examined. The atomic charges were obtained from the optimized geometry at the HF/6-31G* level of theory according to the Mertz-Kollman population analysis scheme. ${ }^{54-55}$ Consecutively, partial atomic charges were derived according to the RESP protocol, ${ }^{56}$ utilizing the ANTECHAMBER module ${ }^{57}$ of the AMBER12 suite of programs. ${ }^{58}$ General Amber force field 
(GAFF) parameters ${ }^{59}$ were then assigned to both molecules, as they have been successfully employed in conjunction with the CLAYFF model in previous studies. ${ }^{60-62}$ Topologies were generated by means of the tLEaP module..$^{58}$

Finally, $\mathrm{NaCl}, \mathrm{CsCl}, \mathrm{SrCl}_{2}$ and $\mathrm{RaCl}_{2}$ water-based fracturing fluids of approximately $0.3 \mathrm{M}$ salt concentration containing $5 \%$ wt of either methanol or citric acid were prepared by appropriately replacing water molecules with electrolyte ions. For the description of ion parameters the hydration free energy (HFE) set that is specifically parametrized for the SPC/E water by Li et al. was used. ${ }^{63-64}$ As far as the fully deprotonated citric acid systems are concerned and in order to maintain the salt ion balance, charge neutrality was achieved by introducing oxidanium $\left(\mathrm{H}_{3} \mathrm{O}^{+}\right)$ions. ${ }^{63}$ It should be noted that these counterbalance cations by no means bear any implications in terms of kaolinite's surface coverage and the system $\mathrm{pH}$. Such $\mathrm{pH}$ variations were not examined, kaolinite surfaces remain neutral and only citric acid was varied between two protonation states. Detailed compositions of all systems examined are presented in Table 1. Atom types, partial charges and force field parameters of all species are collected in Tables S1-S6 of the Supporting Information.

\subsection{Simulation details}

All MD simulations were performed using the GROMACS 5.0.7 software. ${ }^{65-70}$ The generated GAFF topologies were converted to the GROMACS format by means of the ACPYPE utility (Table S6). ${ }^{71}$ The simulations were performed in orthorhombic boxes, with periodic boundary conditions imposed in all directions (see Figure 1) at ambient conditions of temperature (298.15 $\mathrm{K})$ and pressure (1 bar). These conditions are only relevant to the ones encountered at earth's surface but also correspond to the CLAYFF force field parameterization. ${ }^{44}$ 
Prior to production runs and in order to eliminate any overlap between atoms, all systems were subjected to steepest descent energy minimization for 20,000 steps. Then, short equilibration simulations in the canonical $(N V T)$ and isobaric-isothermal $(N p T)$ ensembles were performed. Specifically, all systems were gradually heated to the target temperature of $298.15 \mathrm{~K}$ for $100 \mathrm{ps}$ in the $N V T$ ensemble using the Berendsen thermostat, ${ }^{72}$ with the coupling constant set to 1 ps. The LINCS algorithm ${ }^{73}$ restrained all bonds involving hydrogen atoms. The integration step of all simulations was set to 2 fs. A simple cut-off scheme for the Lennard-Jones (LJ) interactions can have minor impact on the molecular arrangement, but can significantly influence simulations of inhomogeneous systems, leading to incorrect estimation of interfacial properties. ${ }^{74}$ Therefore, we applied the Particle Mesh Ewald (PME) method ${ }^{75-76}$ for the long-range LJ interactions as well as for electrostatic interactions ${ }^{77}$ with a cut-off at $1.2 \mathrm{~nm}$ for the short-range interactions. The Lorentz-Berthelot combining rules ${ }^{78}$ were used for the cross-interaction LJ parameters.

All systems were initially equilibrated for a period of $1 \mathrm{~ns}$ in the $\mathrm{NpT}$ ensemble, at constant pressure of 1 bar using a Berendsen barostat, ${ }^{72}$ with the coupling constant set to 1 ps. Pressure coupling was isotropic in the $\mathrm{x}$ and $\mathrm{y}$ direction, but semi-isotropic in the $\mathrm{z}$ direction, which is perpendicular to the fluid-kaolinite interface. All systems were further equilibrated for $4 \mathrm{~ns}$ using the Nosé-Hoover thermostat, ${ }^{79}$ while isotropic pressure was maintained using a ParrinelloRahman barostat ${ }^{80}$ with a coupling constant set to 5 ps. During the $5 \mathrm{~ns}$ period, the density of the liquid phase converged to a mean value, along with the energy of the system. Finally, production runs of $100 \mathrm{~ns}$ were performed in the $N V T$ ensemble and all analysis was carried out over the last $40 \mathrm{~ns}$ of the simulations.

In order to examine the role of hydrogen bonds in the adsorption behavior of the various species examined in this work, we analyzed the hydrogen bond (HB) structure between the 
kaolinites surfaces and the water molecules as well as between the kaolinite surfaces and the additives. Traditional geometrical criteria were used, where a hydrogen bond is defined to exist if the donor-acceptor distance is less than $r_{\mathrm{HB}}=0.35 \mathrm{~nm}$ and simultaneously the hydrogen-donoracceptor angle is less than $\alpha_{\mathrm{HB}}=30^{\circ}{ }^{81}$ Following the approach of Zhang et al. ${ }^{41}$ the number of HBs was normalized to a surface area of $10 \mathrm{~nm}^{2}$.

Furthermore, the aggregation of citric acid molecules was investigated by means of the g_clustsize program. ${ }^{69}$ The first minimum of the intermolecular oxygen-oxygen radial distribution function (RDF) of citric acid was used as the distance cutoff criterion for the evaluation of aggregates, hence the minimum distance between molecules considered as part of an aggregate was less than 0.40 and $0.45 \mathrm{~nm}$ for $\mathrm{H}_{3} \mathrm{~A}$ and $\mathrm{A}^{3-}$, respectively (Figure $\mathrm{S} 1$ ). Ions close to citric acid aggregates were dynamically selected based on their first RDF minimum (Figure S2).

The mobility of the components of the system is an indication of their tendency to be adsorbed on the surfaces of the slit pore (adsorption strength). Given that the width of the kaolinite pore in the present work is approximately $4 \mathrm{~nm}$, it is expected that near its center, the lateral diffusion resembles that of the bulk solution, while near the surfaces the mobility is reduced due to the interactions developed between the compounds and the surface. To this respect, the analysis of the molecular motion as a function of the distance from kaolinite surfaces was performed by means of lateral diffusion coefficients. Since the system is an aqueous solution under confinement, it is reasonable to divide the pore in three main regions based on the mass/molecule axial density profile of water along the confinement direction (i.e. $z$ in our study). Furthermore, the restricted length of the slabs due to confinement poses a problem in the calculation of the self-diffusion coefficients, given that results in low mean residence times are lower that the time needed for the Fickian diffusion to be developed. Therefore, for these cases we calculated indicative diffusion 
coefficients from the slope of the mean square displacement $(M S D)$ versus time curve at the point of the corresponding mean residence time of the component in the slab. The lateral MSD of the component $i$ was calculated as:

$$
M S D_{x y}^{i}=\left\langle\left(x_{t}-x_{0}\right)^{2}+\left(y_{t}-y_{0}\right)^{2}\right\rangle
$$

where, the brackets denote the mean value over all molecules of component $i$ and multiple origins. In the case where sampling is efficient and the diffusion has entered the Fickian region the lateral self-diffusion coefficient was calculated from the well-known formula:

$$
M S D_{x y}^{i}=4 D_{x y}^{i} t
$$

\section{Results and Discussion}

\section{i. Density profiles}

In Figure 2, we present the density distributions along the axis normal to the kaolinite walls (which are separated by approximately $4 \mathrm{~nm}$ ) for $\mathrm{NaCl}, \mathrm{CsCl}, \mathrm{SrCl}_{2}$ and $\mathrm{RaCl}_{2}$ containing systems with and without methanol. In all cases, the distribution of water in the kaolinite pore is not affected by the presence of methanol. A slight shift in water distribution is due to the difference in system size, as the number of water molecules was adjusted to counterbalance the addition of methanol and maintain the same mass density inside the pore's volume and the concentration of the additives. The water distribution is fairly symmetric and shows two peaks on both sides, indicative of two layers of adsorption. This is also true for all systems examined. The subtle differences in water distribution observed are attributed to the different nature of the two kaolinite pore surfaces. These layers can be used in characterizing the ion's adsorption behavior as inner-sphere or outer-sphere. As outer-sphere adsorption we characterize the behavior of ions which are in proximity to a surface 
but still retain fully their hydration shell, whereas as inner-sphere the case where the ions have lost part of their hydration shell in order to approach the surface. ${ }^{15}$

In all systems examined, the negatively charged $\mathrm{Cl}^{-}$ion is found on the octahedral hydroxylated gibbsite surface (left side), and exhibits inner-sphere adsorption, given that it is primarily found within the first water layer. On the other hand, $\mathrm{Na}^{+}, \mathrm{Cs}^{+}, \mathrm{Sr}^{2+}$ and $\mathrm{Ra}^{2+}$ cations are found primarily on the siloxane surface (right side). $\mathrm{Na}^{+}$shows outer-sphere adsorption behavior on the siloxane surface, and the same is true for $\mathrm{Sr}^{2+}$ and $\mathrm{Ra}^{2+}$. On the contrary, $\mathrm{Cs}^{+}$exhibits mainly inner-sphere adsorption, while a considerable concentration is also located at the outer-sphere. The adsorption behavior of $\mathrm{Cl}^{-}, \mathrm{Na}^{+}$and $\mathrm{Cs}^{+}$is consistent with the findings of Vasconcelos et al. ${ }^{15}$

Methanol closely follows the distribution of water in the bulk-like region of the pore and it shows greater preference towards the siloxane surface. In Figure S3a, a snapshot of methanol close to the siloxane surface is illustrated. In general, the hydrogen of the hydroxyl group is directed towards both the surface and the bulk region, while the carbon of the carbon-oxygen bond is mainly directed towards the siloxane surface. This is supported by the atomic number density profiles (Figure $\mathrm{S} 3 \mathrm{~b}$ ) and polar angle probability distributions of the $\mathrm{C}-\mathrm{O}\left(\theta_{\mathrm{C}-\mathrm{O}}\right)$ and $\mathrm{O}-\mathrm{H}$ bonds $\left(\theta_{\mathrm{O}-\mathrm{H}}\right)$ in the siloxane and gibbsite regions (Figure S3c). In all cases, the presence of methanol does not affect the ion distribution and vice versa.

For the case of citric acid, we examine both fully protonated $\left(\mathrm{H}_{3} \mathrm{~A}\right)$ and deprotonated $\left(\mathrm{A}^{3-}\right)$ forms. As a baseline, we present in Figure 3 the distribution within the kaolinite pore of the $\mathrm{H}_{3} \mathrm{~A}$ citric acid in the absence of salts. Citric $\mathrm{H}_{3} \mathrm{~A}$ preferentially adsorbs on the siloxane surface but it is also found to a lesser extent on the gibbsite side. On the siloxane side, its distribution follows that of water and resembles that of methanol. Citric acid $\mathrm{H}_{3} \mathrm{~A}$ aggregates tend to form in the whole range of the pore, which is discussed in more detail in a subsequent section. 
In Figure 4, we present the results for systems containing $\mathrm{NaCl}, \mathrm{CsCl}, \mathrm{SrCl}_{2}$ and $\mathrm{RaCl}_{2}$ with and without $\mathrm{H}_{3} \mathrm{~A}$. The protonated (or non-dissociated) form of citric acid in general does not shift the distribution of the ions for all the cases examined. On the contrary, the distribution of $\mathrm{H}_{3} \mathrm{~A}$ is affected by the ion presence. Although its adsorption behavior on the siloxane side remains practically unaffected, its concentration is slightly increased in the bulk and marginally towards the gibbsite side An exception to the above behavior is found for aqueous systems containing $\mathrm{CsCl}$, in which case citric acid closely follows the distribution of $\mathrm{Cs}^{+}$, concentrated on the siloxane surface.

The distribution of the fully deprotonated form of citric acid, $\mathrm{A}^{3-}$, is vastly different from that of the protonated form. In Figure 3, the distribution of $\mathrm{A}^{3-}$ is presented in the absence of salts. It is observed that $\mathrm{A}^{3-}$ is located mainly on the gibbsite side, as the negatively charged carboxylate groups are attracted to the hydroxyls of the surface. Its non-uniform distribution implies a tendency for cluster formation, which encompasses cations such as oxidanium or the cations of the salts. This is analyzed further in the subsequent sections. In Figure 5, the distributions of the aqueous solutions of $\mathrm{NaCl}, \mathrm{CsCl}, \mathrm{SrCl}_{2}$ and $\mathrm{RaCl}_{2}$ with and without $\mathrm{A}^{3-}$ are shown. The presence of $\mathrm{Na}^{+}$, $\mathrm{Sr}^{2+}$ and $\mathrm{Ra}^{2+}$ shifts the $\mathrm{A}^{3-}$ distribution towards the siloxane surface. Exception is the case of $\mathrm{Cs}^{+}$ which, as shown in Figure $5 \mathrm{~b}$, does not allow $\mathrm{A}^{3-}$ citric acid to approach the siloxane side but restricts its presence to the gibbsite side. While in most cases examined here citric $\mathrm{A}^{3-}$ does not alter the distribution of the ions significantly, it was observed that $\mathrm{Cs}^{+}$cations were detached from the siloxane side and brought close to the gibbsite surface by $\mathrm{A}^{3-}$ citric clusters (Figure $5 \mathrm{~b}$ ). The oxidanium's distribution in general follows that of $\mathrm{A}^{3-}$. An additional peak can be found on the siloxane side exhibiting outer-sphere adsorption. 


\section{ii. Hydrogen bond network}

Hydrogen bond (HB) analysis between water and kaolinite surface proton donors and acceptors revealed changes in water-surface affinity as a function of mixture composition. From the results presented in Figure 6, it becomes apparent that when kaolinite contains pure water without salts or additives, water forms more HBs on the gibbsite surface compared to its siloxane counterpart, which acts primarily as a proton donor, in agreement with previous simulations. ${ }^{41}$ The gibbsite side has a higher number of hydrogen bonds $\left(\mathrm{N}_{\mathrm{HB}}\right)$ compared to the siloxane side upon addition of either salts or additives. Furthermore, addition of salts results in a reduction of water-surface HBs on both surfaces, but particularly on the siloxane surface. Inner-sphere adsorption of $\mathrm{Cl}^{-}$anions on the gibbsite hydroxylated side results in the same reduction of $\mathrm{N}_{\mathrm{HB}}$ in all systems. The total $\mathrm{N}_{\mathrm{HB}}$ in $\mathrm{NaCl}, \mathrm{SrCl}_{2}$ and $\mathrm{RaCl}_{2}$ containing systems is almost the same, with the exception of $\mathrm{CsCl}$, which exhibits reduction at the siloxane surface. This analysis demonstrates that inner-sphere adsorption of $\mathrm{Cs}^{+}$is affecting water-kaolinite $\mathrm{HB}$ behavior.

Adding methanol and $\mathrm{H}_{3} \mathrm{~A}$ yields similar effects on the $\mathrm{HB}$ network (Figure 6); in both cases the number of HBs between water and the gibbsite surface remains unaffected compared to pure water $\left(\mathrm{Kao}-\mathrm{H}_{2} \mathrm{O}\right)$. On the other hand, adding $\mathrm{A}^{3-}$ leads to a small reduction of $\mathrm{HBs}$ on the gibbsite side. At the siloxane surface, the presence of additives considerably reduces $\mathrm{N}_{\mathrm{HBS}}$. The same holds for the systems containing both additives and salts. Notably, $\mathrm{CsCl}$ systems show a greater reduction of $\mathrm{N}_{\mathrm{HB}} \mathrm{S}$, compared to the rest salt containing systems.

As shown in Figure 7a, methanol is not involved in extensive HB formation with either surface. This behavior is not changed by the addition of salts. This agrees with our previous observation that methanol does not show preference towards the gibbsite side and that on the 
siloxane side its hydroxyl group is not always directed towards the surface. As with water, the gibbsite surface acts as a HB donor.

Results are presented in Figure $7 \mathrm{~b}$ for the hydrogen bonds between the kaolinite surfaces and the oxygens of the citric acid. Interestingly, citric acid in its fully protonated state $\left(\mathrm{H}_{3} \mathrm{~A}\right)$ forms a slightly higher number of $\mathrm{HBs}$ with the gibbsite wall in the systems containing $\mathrm{NaCl}, \mathrm{SrCl}_{2}$ and $\mathrm{RaCl}_{2}$ compared to the salt-free system, whereas this number is diminished in the $\mathrm{CsCl}$ system. In all cases however, HBs at the siloxane side remain at very low levels. On the other hand, $\mathrm{A}^{3-}$ molecules form extensive HBs with the gibbsite surface hydroxyls in the salt-free system, which drop dramatically with the addition of salts. This is attributed to the presence of $\mathrm{Cl}^{-}$anions, which limit the availability of $\mathrm{HB}$ contacts with the surface. $\mathrm{N}_{\mathrm{HB}}$ is further reduced in the $\mathrm{SrCl}_{2}$ and $\mathrm{RaCl}_{2}$

containing systems, where the $\mathrm{Cl}^{-}$concentration is doubled and $\mathrm{A}^{3-}$ molecules move further away from the gibbsite surface shifting closer to the siloxane side, with which -however- no HBs are formed.

\section{iii. Citric acid aggregate}

To quantify the size of citric acid aggregates, we performed a clustering analysis. The results are presented in Figures 8 and 9. For the case of the $\mathrm{H}_{3} \mathrm{~A}$, the average number of aggregates fluctuates around $4.3( \pm 1.2)$ for the salt free system and $4.4( \pm 1.2), 3.1( \pm 1.1), 4.7( \pm 1.0)$ and $4.5( \pm 1.3)$ in systems containing $\mathrm{NaCl}, \mathrm{CsCl}, \mathrm{SrCl}_{2}$ and $\mathrm{RaCl}_{2}$, respectively (Figure 8a), with values in parentheses denoting standard deviation. In addition, as illustrated in Figure 9a, the average aggregate size of $\mathrm{H}_{3} \mathrm{~A}$ contains $3.5( \pm 1.2)$ in the salt-free system and $2.7( \pm 0.5), 6.3( \pm 2.6), 3.2$ $( \pm 0.6)$ and $3.2( \pm 1.0)$ molecules in $\mathrm{NaCl}, \mathrm{CsCl}, \mathrm{SrCl}_{2}$ and $\mathrm{RaCl}_{2}$ containing systems, respectively. This means that $\mathrm{H}_{3} \mathrm{~A}$ molecules tend to coalesce into many small aggregates (mainly dimers and trimers), without showing any tendency to accumulate in larger formations, regardless of salt. 
These small aggregates change dynamically during the simulation, with individual molecules leaving one cluster and adsorbing to another. With the exception of the $\mathrm{CsCl}$ system, cations do not show any participation in $\mathrm{H}_{3} \mathrm{~A}$ aggregate formation. As far as the $\mathrm{CsCl}$ system is concerned, $3.9( \pm 1.7) \mathrm{Cs}^{+}$cations participate on average in the small $\mathrm{H}_{3} \mathrm{~A}$ aggregates. This can be attributed to the criterion used for analysis and the fact that citric acid aggregates are found close to the inner sphere adsorbed $\mathrm{Cs}^{+}$. Given that $\mathrm{H}_{3} \mathrm{~A}$ is located on the siloxane side and forms relatively more HBs with the surface compared to other systems, this suggests the formation of bridges between the siloxane oxygen atoms, $\mathrm{Cs}^{+}$cations and carboxyl oxygens. $\mathrm{Cl}^{-}$anions do not participate in $\mathrm{H}_{3} \mathrm{~A}$ aggregates formation in $\mathrm{NaCl}$ and $\mathrm{CsCl}$ systems. However, in the $\mathrm{SrCl}_{2}$ and $\mathrm{RaCl}_{2}$ containing systems $1.0( \pm 0.4) \mathrm{Cl}^{-}$anion was found on average in the aggregates formed.

On the contrary, the fully dissociated $\mathrm{A}^{3-}$ molecules progressively aggregate to form large clusters (Figure 8b). This is illustrated by the average number of aggregates present in the last 40 ns, which fluctuates around $4.7( \pm 0.5)$ for the salt free system and $4.7( \pm 0.5), 2.0,3.5( \pm 0.9)$ and $2.1( \pm 0.3)$ in systems with $\mathrm{NaCl}, \mathrm{CsCl}, \mathrm{SrCl}_{2}$ and $\mathrm{RaCl}_{2}$, respectively. These numbers and their time evolution hint that longer times will yield a small number of aggregates. These formations comprise not only $\mathrm{A}^{3-}$ molecules but also the majority of $\mathrm{H}_{3} \mathrm{O}^{+}$cations, along with other cations present in the system. Specifically, the average aggregate size of $A^{3-}$ contains $5.0( \pm 0.6)$ in the salt-free system and $4.7( \pm 0.5), 11.3( \pm 0.2), 7.1( \pm 2.1)$ and $11.0( \pm 1.3)$ molecules in $\mathrm{NaCl}, \mathrm{CsCl}$, $\mathrm{SrCl}_{2}$ and $\mathrm{RaCl}_{2}$ systems, respectively (Figure $9 \mathrm{~b}$ ). These aggregates also contain on average of $10.4( \pm 1.3) \mathrm{H}_{3} \mathrm{O}^{+}$cations in the salt-free system, which increases to $11.2( \pm 1.3), 26.6( \pm 0.4), 15.5$ $( \pm 4.5)$ and $24.6( \pm 2.7) \mathrm{H}_{3} \mathrm{O}^{+}$cations in $\mathrm{NaCl}, \mathrm{CsCl}, \mathrm{SrCl}_{2}$ and $\mathrm{RaCl}_{2}$ systems, respectively (Figure $9 b)$. The prevalent role of $\mathrm{H}_{3} \mathrm{O}^{+}$in cluster formation is also revealed through the coordination number of the $\mathrm{A}^{3-}$ oxygens with the various ions, which is calculated through integration of their 
respective RDFs up to the first minimum (Figure S2) and shown in Figure $10 . \mathrm{H}_{3} \mathrm{O}^{+}$cations essentially act as bridges connecting the $-\mathrm{COO}^{-}$groups and are integral in aggregate formation. The trends observed in the average $\mathrm{H}_{3} \mathrm{O}^{+}$aggregate content are also present in the participating cations. In detail, $\mathrm{A}^{3-}$ aggregates contain $2.0( \pm 0.5), 1.5( \pm 0.4), 6.2( \pm 1.8)$ and $7.9( \pm 1.1) \mathrm{Na}^{+}$, $\mathrm{Cs}^{+}, \mathrm{Sr}^{2+}$ and $\mathrm{Ra}^{2+}$ cations, respectively (Figure $9 \mathrm{~b}$ ). It is important to note that $\mathrm{Cs}^{+}$is not a major aggregate contributor. This is probably due to its inner sphere mode of adsorption on kaolinite's siloxane surface, which renders detachment by $\mathrm{A}^{3-}$ less favorable compared to other cations and is in agreement with adsorption energies presented in previous studies. ${ }^{15}$ However, in case that $\mathrm{Cs}^{+}$ is dislocated, it participates in $\mathrm{A}^{3-}$ aggregates by acting as a bridge to the hydroxylated side (Figure 11). $\mathrm{Cl}^{-}$anions were not found to participate in aggregates formed in the $\mathrm{NaCl}$ system. In the $\mathrm{CsCl}$, $\mathrm{SrCl}_{2}$ and $\mathrm{RaCl}_{2}$ containing systems, $2.5( \pm 0.4) \mathrm{Cl}^{-}$anions were calculated on average in the aggregates formed. As with the salt-free system, these clusters tend to approach the hydroxylated side of the kaolinite mesopore in the $\mathrm{NaCl}$ and $\mathrm{CsCl}$ containing systems. This is not the case, however, for the systems containing divalent $\mathrm{Sr}^{2+}$ and $\mathrm{Ra}^{2+}$ cations, where the aggregates lie closer to the siloxane side (Figure 5) due to the electrostatic interactions.

As mentioned previously, the tendency is to finally have only a small number of aggregates present (Figure 9b), which is more pronounced in salt containing systems compared to its salt-free counterpart. To this end, we have repeated simulations and performed independent runs for 300 ns, showing that in the $\mathrm{NaCl}, \mathrm{SrCl}_{2}$ and $\mathrm{RaCl}_{2}$ containing systems a single large aggregate is formed (Figure $\mathrm{S} 4$ ). In the $\mathrm{CsCl}$ system, two large aggregates are formed, whereas in the salt-free system four aggregates appear stable during the $300 \mathrm{~ns}$ simulations. This shows that the presence of salts is an important factor for aggregation. Finally, we repeated these simulations in the absence of kaolinite walls. The same aggregation behavior was observed for the salt containing $\mathrm{A}^{3-}$ 
systems. In the pure $\mathrm{A}^{3-}$ system a single aggregate was formed, indicating that confinement is a determining factor in aggregate formation (Figure S5).

\section{iv. Component mobility}

In Figure 12, the calculated self-diffusion coefficients and residence times of all fluid components are presented. In order to evaluate the mobility of fluid components inside the slit pore, the space between the two surfaces was partitioned into three regions along the confinement direction. Based on the axial density profiles of water (Figures 2-4) three regions were defined. The first region (RI) includes the two adsorption layers of the gibbsite surface; the second (RII) corresponds to the bulk solution while the two adsorption layers of the siloxane surface define the third region (RIII). The diffusion coefficients and the residence times of the components were calculated in each of the aforementioned regions. Due to the small/limited thickness of the slabs, the lateral diffusion coefficients were estimated using two approaches i.e., either from the slope of the $M S D(t)$ curve in the region of Fickian diffusion or, if this was not possible, from the slope of the curve at time equal to the mean residence time of the considered component. Moreover, the residence times at the regions RI and RIII are directly comparable since these slabs are of equal thickness.

In all cases, component mobility is reduced in the regions near kaolinite surfaces compared to the bulk, with the decrease being more profound in the proximity of the gibbsite side. Methanol addition has a marginal impact in the fluid behavior. In agreement with experiments, the diffusion coefficients of the bulk water (middle slab) are slightly reduced upon mixing with methanol. ${ }^{82}$ This is also the case for diffusion coefficients of all the ions in the bulk and siloxane regions while $D_{\text {xy }}$ remains practically unchanged in the gibbsite side. The order of calculated $D_{\mathrm{xy}}$ in the bulk is $\mathrm{Cs}^{+}$ 
$>\mathrm{Na}^{+}>\mathrm{Sr}^{2+}>\mathrm{Ra}^{2+}$. Our results are in agreement with available experimental data for the case of $\mathrm{Cs}^{+}$and $\mathrm{Na}^{+}$for the bulk system. ${ }^{83}$ The higher values of $\mathrm{Cs}^{+}$diffusion coefficient in the middle slab, in comparison to the other cations, can be attributed to the increased van der Waals interaction of $\mathrm{Cs}^{+}$with water and partially to the lower concentration of $\mathrm{Cs}^{+}$in the bulk (since it exhibits increased preference towards kaolinite's surfaces compared to the other cations and therefore its concentration in the bulk region is relatively reduced).

The ranking of cation residence times near the siloxane surface is $\mathrm{Ra}^{2+} \geq \mathrm{Sr}^{2+}>\mathrm{Cs}^{+}>\mathrm{Na}^{+}$. On the gibbsite side, residence times of the $\mathrm{Cl}^{-}$anion follow the order $\mathrm{CsCl} \geq \mathrm{NaCl}>\mathrm{RaCl}_{2} \geq$ $\mathrm{SrCl}_{2}$ in the respective systems (Figure 12b). The addition of methanol leaves the residence times unaffected except in the case of $\mathrm{Cl}^{-}$, which presents improved affinity to the gibbsite surface. The observed ordering is connected with the surface-ions interactions and possibly implies differences in the adsorption strengths.

For the citric acid solutions, cluster formation renders the $D_{\text {xy }}$ calculation arduous. Nevertheless, it is possible to estimate the diffusion coefficient for the water and the cations present in the solution. It is observed for both citric acid models that the mobility of these components is reduced compared to the corresponding pure salt solutions. For water in the bulk region, this reduction is more profound in the dissociated model case. At the siloxane side, the aforementioned components appear less mobile in the case of the non-dissociated citric acid model. This is correlated with the larger affinity of the $\mathrm{H}_{3} \mathrm{~A}$ with the siloxane surface, as described in the previous paragraphs. The mobility of the $\mathrm{H}_{3} \mathrm{O}^{+}$cations in the bulk slab is increasing in the order $\mathrm{NaCl}>$ $\mathrm{CsCl}>\mathrm{SrCl}_{2}>\mathrm{RaCl}_{2}$ in the respective systems. Finally, the larger $D_{\mathrm{xy}}$ was observed for $\mathrm{Cs}^{+}$as in the case of pure salt and salt-methanol solutions. The different affinity of the citric acid models with each kaolinite surface is clearly depicted in their residence times (Figure S6). In the absence 
of salts, molecules of citric $\mathrm{H}_{3} \mathrm{~A}$ reside in the siloxane side about ten times more that the $\mathrm{A}^{3-}$ molecules while in the gibbsite side around 2.5 times less. Salt addition has a minor effect on these differences. The residence times of salt cations increase with the increase of the cation charge and upon addition of $\mathrm{A}^{3-}$ slightly decrease.

\section{Conclusions}

In the present work, we used atomistic molecular dynamics simulations to examine the adsorption behavior inside kaolinite mesopores of various aqueous solutions of $\mathrm{NaCl}, \mathrm{CsCl}, \mathrm{SrCl}_{2}$ and $\mathrm{RaCl}_{2}$ in combination with methanol and citric acid, additives relevant to drilling fluids and extraction of gas and oil trapped in shale reservoirs. Citric acid was modeled in both its fully dissociated $\left(\mathrm{A}^{3-}\right)$ and non-dissociated $\left(\mathrm{H}_{3} \mathrm{~A}\right)$ states. The adsorption of the various species on the basal surfaces of kaolinite was examined primarily through the density profiles along the normal to the wall axis. The preferential adsorption relatively to the gibbsite and siloxane surfaces of the various species was presented in detail, revealing the inner-sphere adsorption of $\mathrm{Cl}^{-}$on the octahedral gibbsite surface, the inner sphere adsorption of $\mathrm{Cs}^{+}$and the outer-sphere adsorption of $\mathrm{Na}^{+}, \mathrm{Cs}^{+}, \mathrm{Sr}^{2+}$ and $\mathrm{Ra}^{2+}$ on the siloxane surface, respectively. We showed that neither methanol nor citric acid strongly affect the water and ion distributions. In the absence of salts, methanol and citric $\mathrm{H}_{3} \mathrm{~A}$ prefer the siloxane side, while citric $\mathrm{A}^{3-}$ prefers the gibbsite side. The addition of salts does not alter the methanol distribution but affects those of citric acid.

Hydrogen bond analysis between the two kaolinite surfaces and water molecules for the various systems reveals changes in the number of HBs upon the addition of salts and additives. These changes are more pronounced for the siloxane surface. Additionally, it was shown that 
neither methanol nor citric acid interacts significantly with the kaolinite surfaces through hydrogen bonding, with the exception of the water-citric $\mathrm{A}^{3-}$ system.

Citric acid in particular has the tendency, for the systems examined, to form aggregates. We showed that for the non-dissociated form of citric acid $\left(\mathrm{H}_{3} \mathrm{~A}\right)$ these aggregates are relatively small $\left(\mathrm{H}_{3} \mathrm{~A}\right.$ dimers and trimers $)$ and dynamic, while for the citric $\mathrm{A}^{3-}$ there is a constant tendency for aggregation towards large clusters. We showed that citric $\mathrm{A}^{3-}$ aggregation is driven through cation bridging, and particularly through the participation of the cation that we used in order to the total charge of the system. Aggregation behavior is controlled by the salt present and in the case of salt-free citric $\mathrm{A}^{3-}$ by the kaolinite surfaces.

Finally, lateral diffusion coefficients and mean residence times showed that the mobility of the solution components is reduced upon methanol and citric acid addition. $\mathrm{Cs}^{+}$has the largest diffusion coefficients of all the cations in the bulk region of the pore in all systems examined and presents improved affinity to the gibbsite surface among the cations. The order of $D_{\mathrm{xy}}$ in the bulk

region is $\mathrm{Cs}^{+}>>\mathrm{Na}^{+}>\mathrm{Sr}^{2+} \geq \mathrm{Ra}^{2+}$. In the case of citric acid solutions, the residence times clearly indicate the affinity of the $\mathrm{A}^{-3}$ and $\mathrm{H}_{3} \mathrm{~A}$ to the gibbsite and siloxane surfaces, respectively.

\section{ASSOCIATED CONTENT}

The Supporting Information is available free of charge on the ACS Publications website at DOI:

Data about force field parameters for all species, intermolecular oxygen-oxygen and oxygen-ion RDFs of citric acid, atomic number density profiles of methanol on the siloxane surface, probability distribution of the polar angles formed between methanol's $\mathrm{C}-\mathrm{O}$ and $\mathrm{O}-\mathrm{H}$ bonds at kaolinite surfaces with respect to the $z$ axis, time evolution of $\mathrm{A}^{3-}$ aggregates during $300 \mathrm{~ns}$ in 
kaolinite confinement and the bulk, diffusion coefficients and residence times for the components of the $0.3 \mathrm{M}$ salt solutions containing $5 \%$ wt citric acid.

\section{AUTHOR INFORMATION}

\section{Corresponding Authors}

*IGE: ioannis.economou@qatar.tamu.edu

\section{Author Contributions}

The manuscript was written through contributions of all authors. All authors have given approval to the final version of the manuscript.

\section{Acknowledgments}

We are grateful to the European Commission for funding our research under Horizon 2020 Programme for Research and Innovation (Grant Agreement No. 640979) and to Professors Andrey G. Kalinichev and Martin Lísal for fruitful discussions on modelling clays. This work was supported by computational time granted from the Greek Research \& Technology Network (GRNET) in the National High Performance Computing facility - ARIS - under project IDs 002043 and 004035. We are also thankful to the High Performance Computing Center of Texas A\&M University at Qatar for generous resource allocation. Scienomics SARL is acknowledged for providing MAPS software used to generate initial structures of the systems simulated. 
Table 1. Detailed compositions of all systems examined in terms of number of molecules.

\begin{tabular}{|c|c|c|c|c|c|c|c|c|c|c|c|c|c|}
\hline \multirow{3}{*}{ System } & \multicolumn{13}{|c|}{ Component } \\
\hline & \multirow{2}{*}{$\mathrm{H}_{2} \mathrm{O}$} & \multirow{2}{*}{$\mathrm{CH}_{3} \mathrm{OH}$} & \multicolumn{3}{|c|}{ Citric acid } & \multicolumn{2}{|c|}{$\mathrm{NaCl}$} & \multicolumn{2}{|c|}{$\mathrm{CsCl}$} & \multicolumn{2}{|c|}{$\mathrm{SrCl}_{2}$} & \multicolumn{2}{|c|}{$\mathrm{RaCl}_{2}$} \\
\hline & & & $\mathrm{H}_{3} \mathrm{~A}$ & $\mathrm{~A}^{3-}$ & $\mathrm{H}_{3} \mathrm{O}^{+}$ & $\mathrm{Na}^{+}$ & $\mathrm{Cl}^{-}$ & $\mathrm{Cs}^{+}$ & $\mathrm{Cl}^{-}$ & $\mathrm{Sr}^{2+}$ & $\mathrm{Cl}^{-}$ & $\mathrm{Ra}^{2+}$ & $\mathrm{Cl}^{-}$ \\
\hline $\mathrm{KaO}-\mathrm{H}_{2} \mathrm{O}$ & 5097 & & & & & & & & & & & & \\
\hline $\mathrm{KaO}-\mathrm{H}_{2} \mathrm{O}-\mathrm{NaCl}$ & 5009 & & & & & 27 & 27 & & & & & & \\
\hline $\mathrm{KaO}-\mathrm{H}_{2} \mathrm{O}-\mathrm{CsCl}$ & 4844 & & & & & & & 27 & 27 & & & & \\
\hline $\mathrm{KaO}-\mathrm{H}_{2} \mathrm{O}-\mathrm{SrCl}_{2}$ & 4860 & & & & & & & & & 27 & 54 & & \\
\hline Kao- $\mathrm{H}_{2} \mathrm{O}-\mathrm{RaCl}_{2}$ & 4652 & & & & & & & & & & & 27 & 54 \\
\hline Kao- $\mathrm{H}_{2} \mathrm{O}-\mathrm{CH}_{3} \mathrm{OH}$ & 4848 & & & & & & & & & & & & \\
\hline $\mathrm{KaO}-\mathrm{H}_{2} \mathrm{O}-\mathrm{NaCl}-\mathrm{CH}_{3} \mathrm{OH}$ & 4760 & & & & & 27 & 27 & & & & & & \\
\hline Kao- $\mathrm{H}_{2} \mathrm{O}-\mathrm{CsCl}-\mathrm{CH}_{3} \mathrm{OH}$ & 4595 & 140 & & & & & & 27 & 27 & & & & \\
\hline $\mathrm{KaO}-\mathrm{H}_{2} \mathrm{O}-\mathrm{SrCl}_{2}-\mathrm{CH}_{3} \mathrm{OH}$ & 4610 & & & & & & & & & 27 & 54 & & \\
\hline $\mathrm{KaO}-\mathrm{H}_{2} \mathrm{O}-\mathrm{RaCl}_{2}-\mathrm{CH}_{3} \mathrm{OH}$ & 4403 & & & & & & & & & & & 27 & 54 \\
\hline Kao- $\mathrm{H}_{2} \mathrm{O}-\mathrm{H}_{3} \mathrm{~A}$ & 5009 & & & & & & & & & & & & \\
\hline Kao- $\mathrm{H}_{2} \mathrm{O}-\mathrm{NaCl}-\mathrm{H}_{3} \mathrm{~A}$ & 4764 & & & & & 27 & 27 & & & & & & \\
\hline $\mathrm{KaO}-\mathrm{H}_{2} \mathrm{O}-\mathrm{CsCl}-\mathrm{H}_{3} \mathrm{~A}$ & 4599 & & 23 & & & & & 27 & 27 & & & & \\
\hline Kao- $\mathrm{H}_{2} \mathrm{O}-\mathrm{SrCl}_{2}-\mathrm{H}_{3} \mathrm{~A}$ & 4614 & & & & & & & & & 27 & 54 & & \\
\hline $\mathrm{KaO}-\mathrm{H}_{2} \mathrm{O}-\mathrm{RaCl}_{2}-\mathrm{H}_{3} \mathrm{~A}$ & 4406 & & & & & & & & & & & 27 & 54 \\
\hline Kao- $\mathrm{H}_{2} \mathrm{O}-\mathrm{A}^{3-}$ & 5009 & & & & & & & & & & & & \\
\hline $\mathrm{Kao}-\mathrm{H}_{2} \mathrm{O}-\mathrm{NaCl}-\mathrm{A}^{3-}$ & 4764 & & & & & 27 & 27 & & & & & & \\
\hline $\mathrm{KaO}-\mathrm{H}_{2} \mathrm{O}-\mathrm{CsCl}-\mathrm{A}^{3-}$ & 4599 & & & 23 & 69 & & & 27 & 27 & & & & \\
\hline Kao- $\mathrm{H}_{2} \mathrm{O}-\mathrm{SrCl}_{2}-\mathrm{A}^{3-}$ & 4614 & & & & & & & & & 27 & 54 & & \\
\hline Kao- $\mathrm{H}_{2} \mathrm{O}-\mathrm{RaCl}_{2}-\mathrm{A}^{3-}$ & 4406 & & & & & & & & & & & 27 & 54 \\
\hline
\end{tabular}




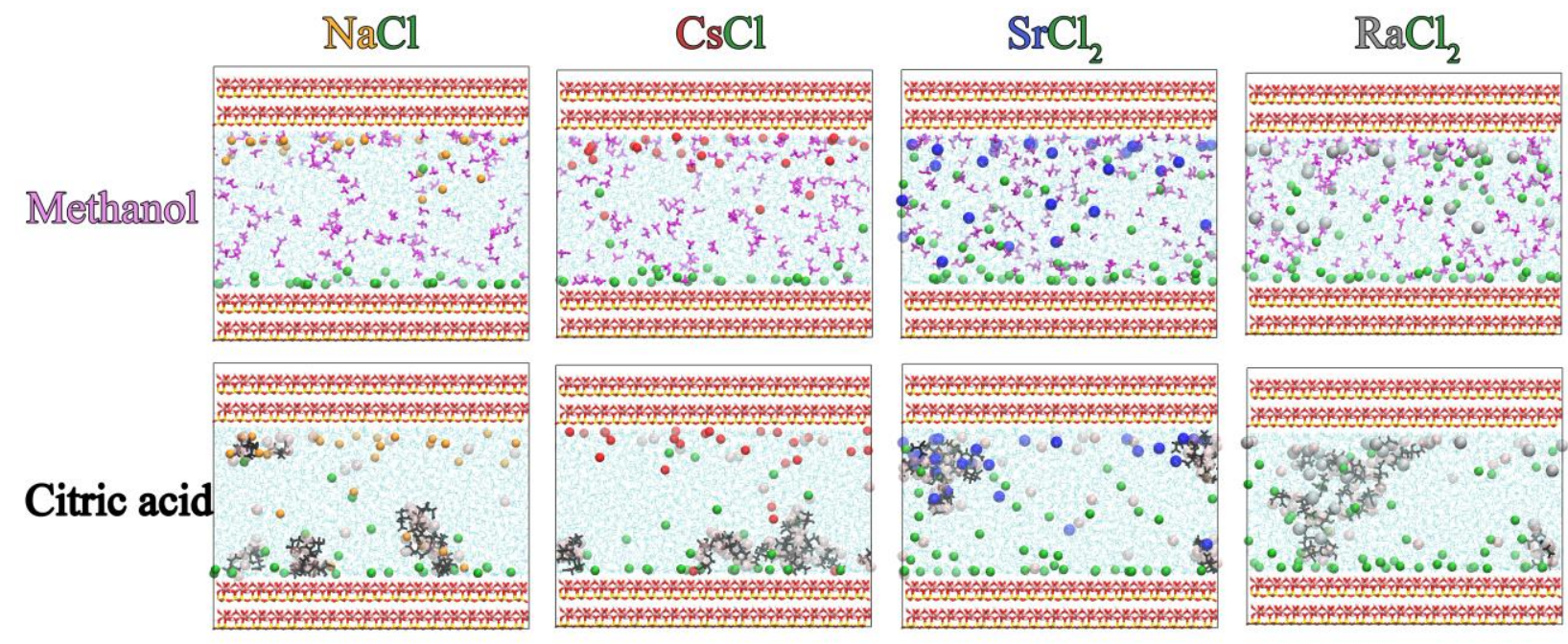

Figure 1. Snapshots of the equilibrated water-based fracturing fluids examined with methanol and citric acid $\left(\mathrm{A}^{3-}\right)$ additives in kaolinite mesopores, including $\mathrm{NaCl}, \mathrm{CsCl}, \mathrm{SrCl}_{2}$ and $\mathrm{RaCl}_{2}$ salts in approximately $0.3 \mathrm{M}$ concentration. 


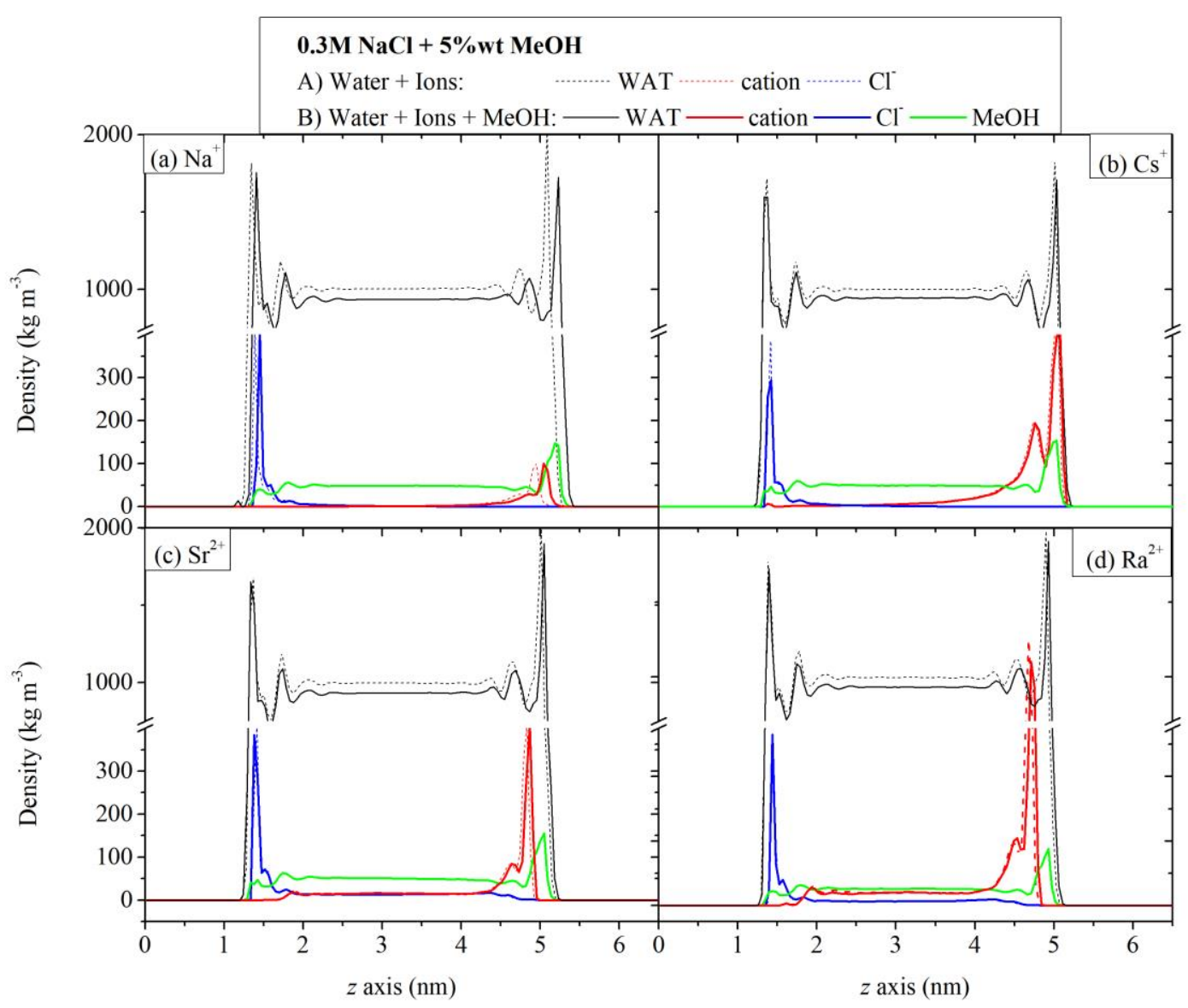

Figure 2. Mass density profiles along the axis normal to the kaolinite mesopore surfaces for the systems with and without methanol. a) $\mathrm{NaCl}$, b) $\mathrm{CsCl}$, c) $\mathrm{SrCl}_{2}$ and d) $\mathrm{RaCl}_{2}$. The left and right sides of each diagram correspond to the gibbsite and siloxane surfaces, respectively. 


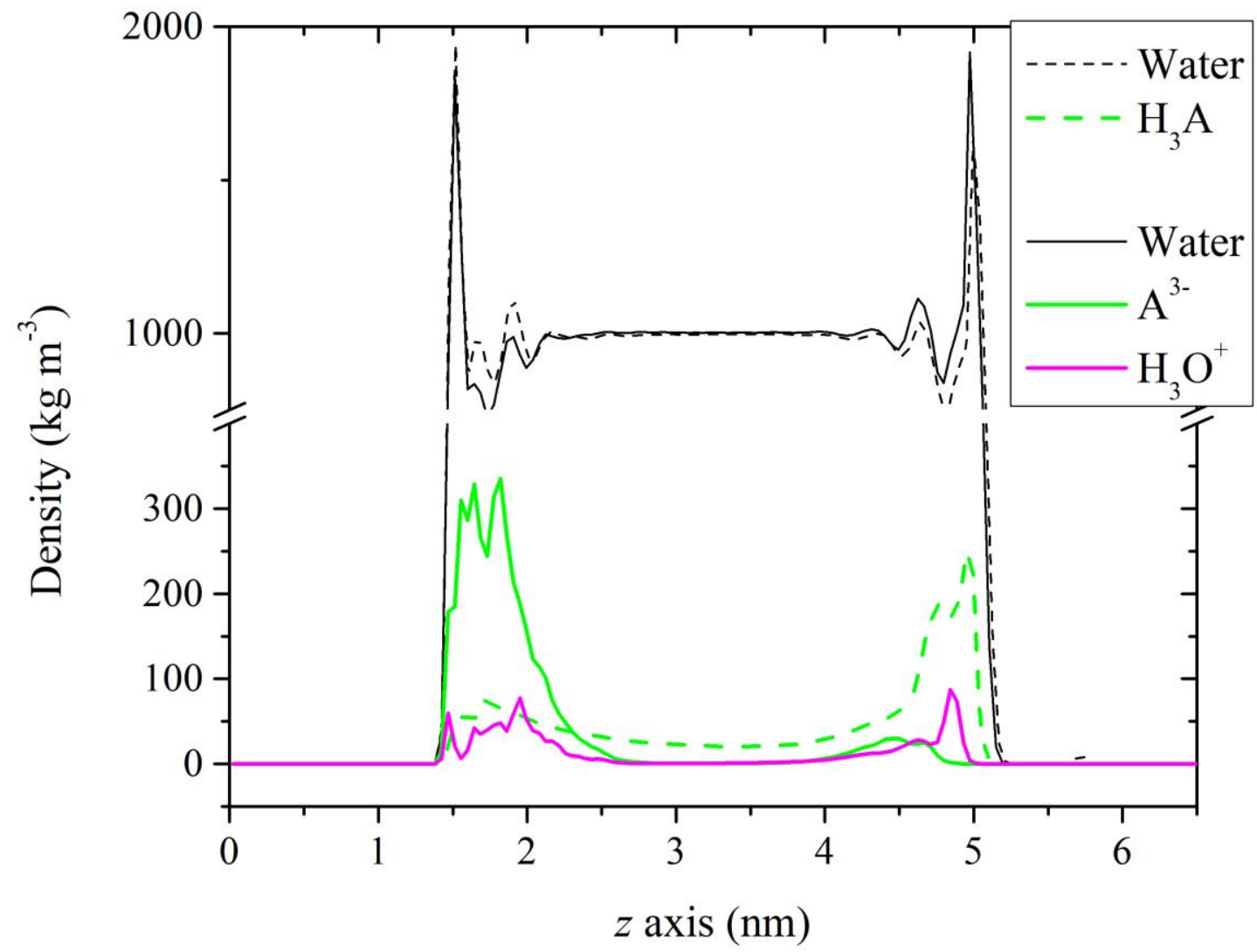

Figure 3. Mass density profiles along the axis normal to the kaolinite mesopore surfaces for the systems of citric acid in the absence of salts. Results for both the protonated $\left(\mathrm{H}_{3} \mathrm{~A}\right)$ and fully deprotonated $\left(\mathrm{A}^{3-}\right)$ forms of citric acid are shown. The left and right sides of the diagram correspond to the gibbsite and siloxane surfaces, respectively. 


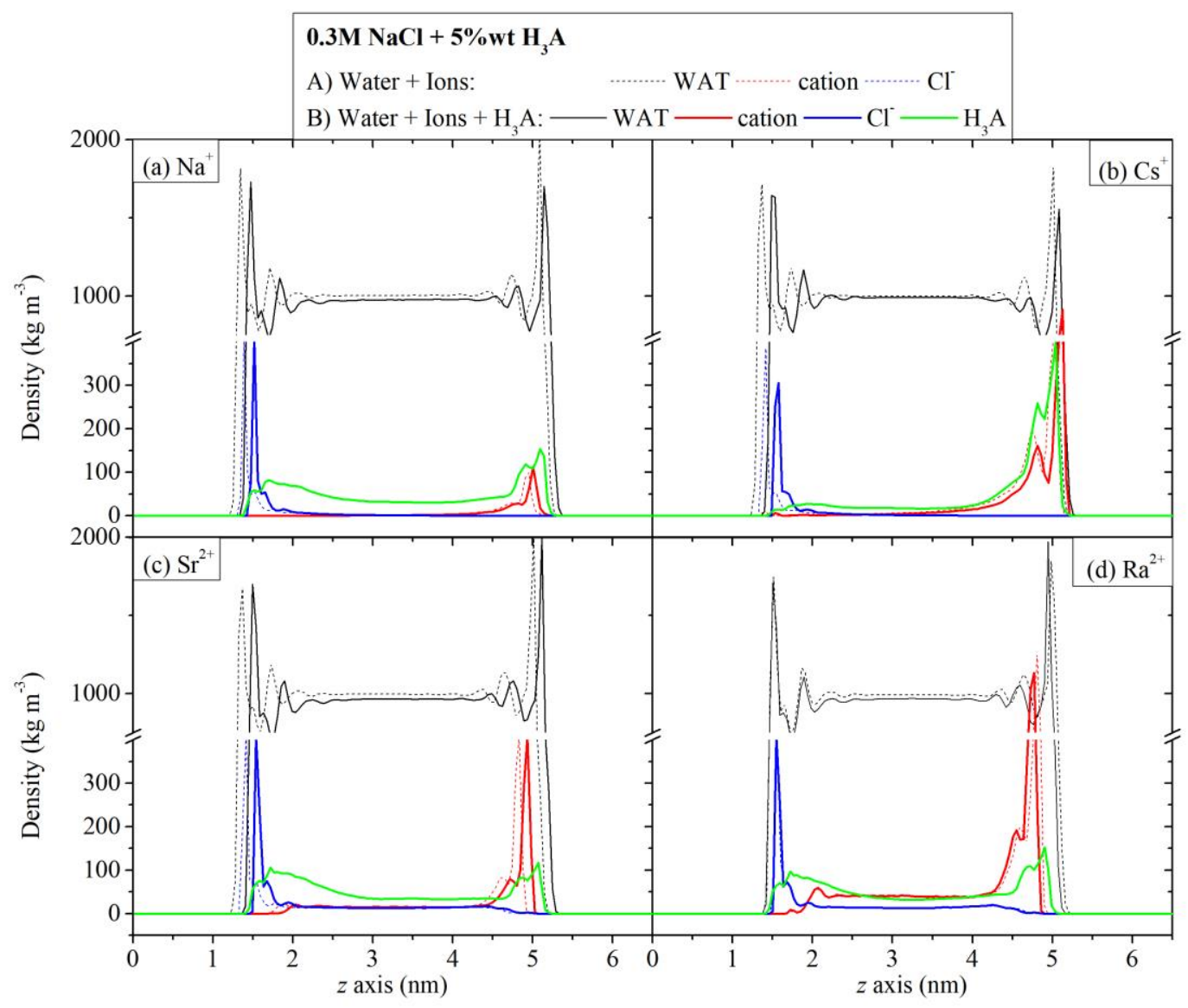

Figure 4. Mass density profiles along the axis normal to the kaolinite mesopore surfaces for the systems with and without the protonated citric acid ( $\left.\mathrm{H}_{3} \mathrm{~A}\right)$. a) $\mathrm{NaCl}$, b) $\mathrm{CsCl}$, c) $\mathrm{SrCl}_{2}$ and d) $\mathrm{RaCl}_{2}$. The left and right sides of each diagram correspond to the gibbsite and siloxane surfaces, respectively. 


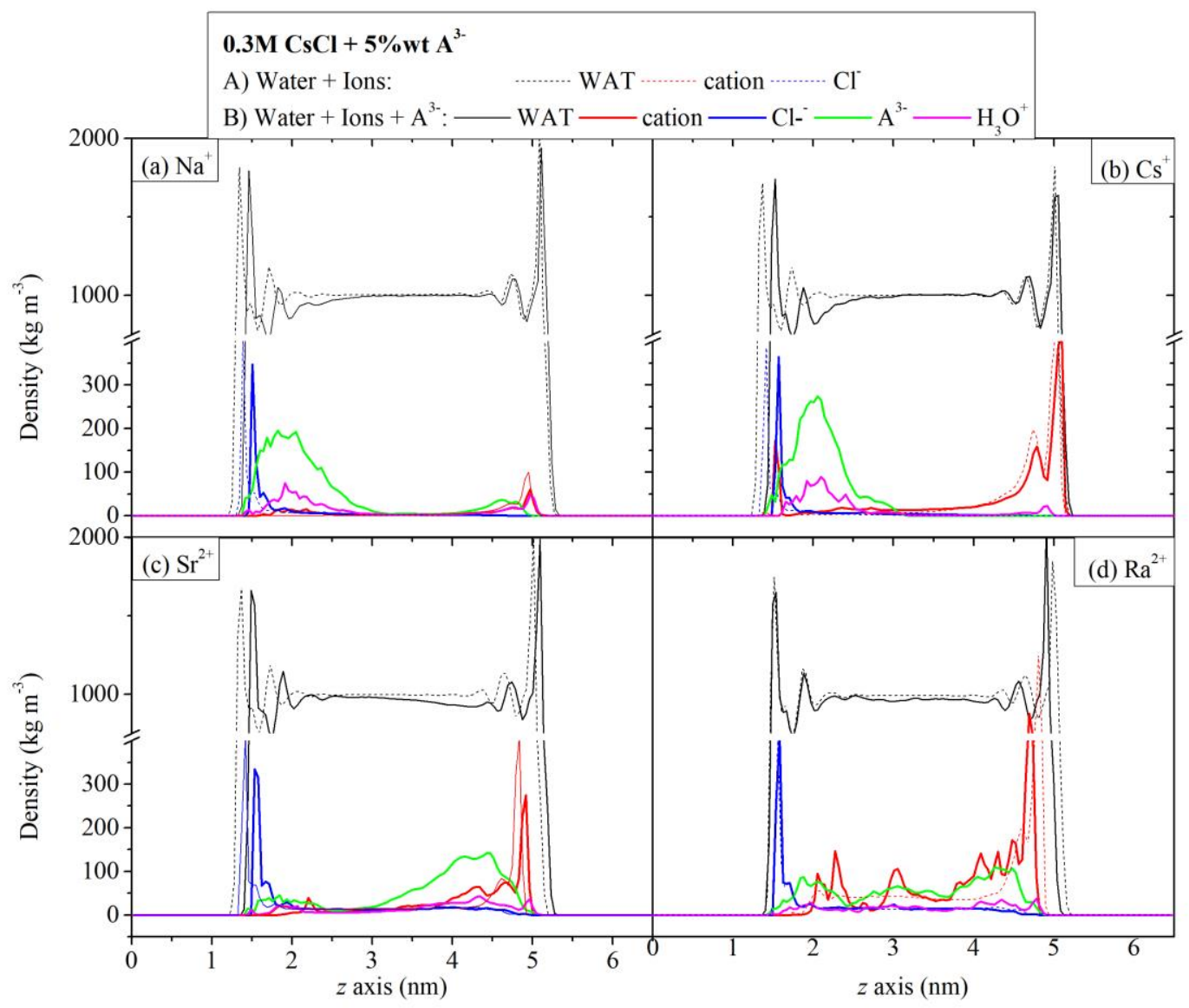

Figure 5. Mass density profiles along the axis normal to the kaolinite mesopore surfaces for the systems with and without the fully deprotonated citric acid $\left(\mathrm{A}^{3-}\right)$. a) $\mathrm{NaCl}$, b) $\mathrm{CsCl}$, c) $\mathrm{SrCl}_{2}$ and d) $\mathrm{RaCl}_{2}$. The left and right sides of each diagram correspond to the gibbsite and siloxane surfaces, respectively. 

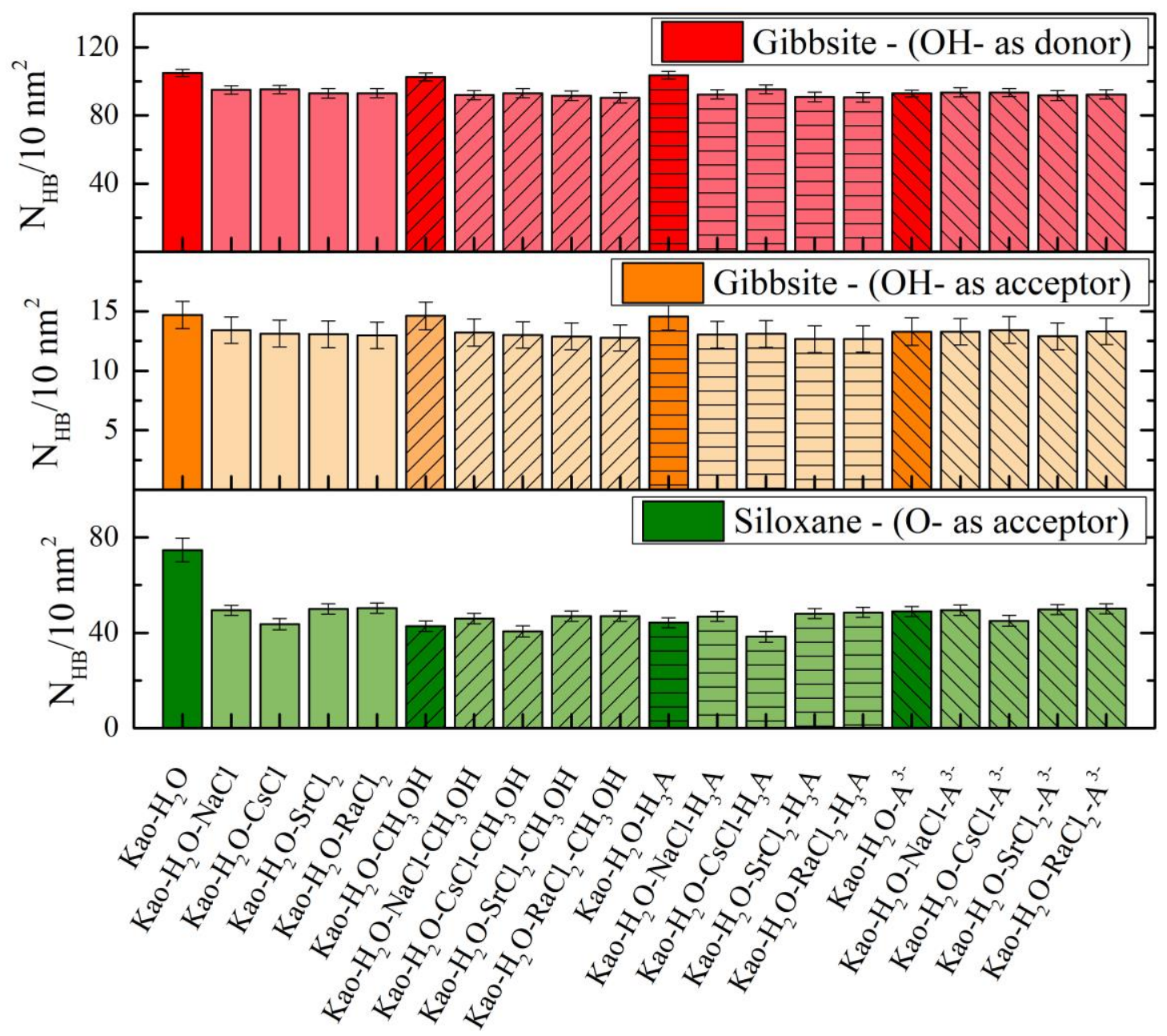

Figure 6. Number of hydrogen bonds, $\mathrm{N}_{\mathrm{HB}}$, between the kaolinite surfaces and water molecules, normalized over a $10 \mathrm{~nm}^{2}$ surface area. Dark and pale colors illustrate systems without and with salt, respectively. Systems containing methanol and citric acid additives are illustrated with stripes. Donor and acceptor refer to proton donor and proton acceptor, respectively. 

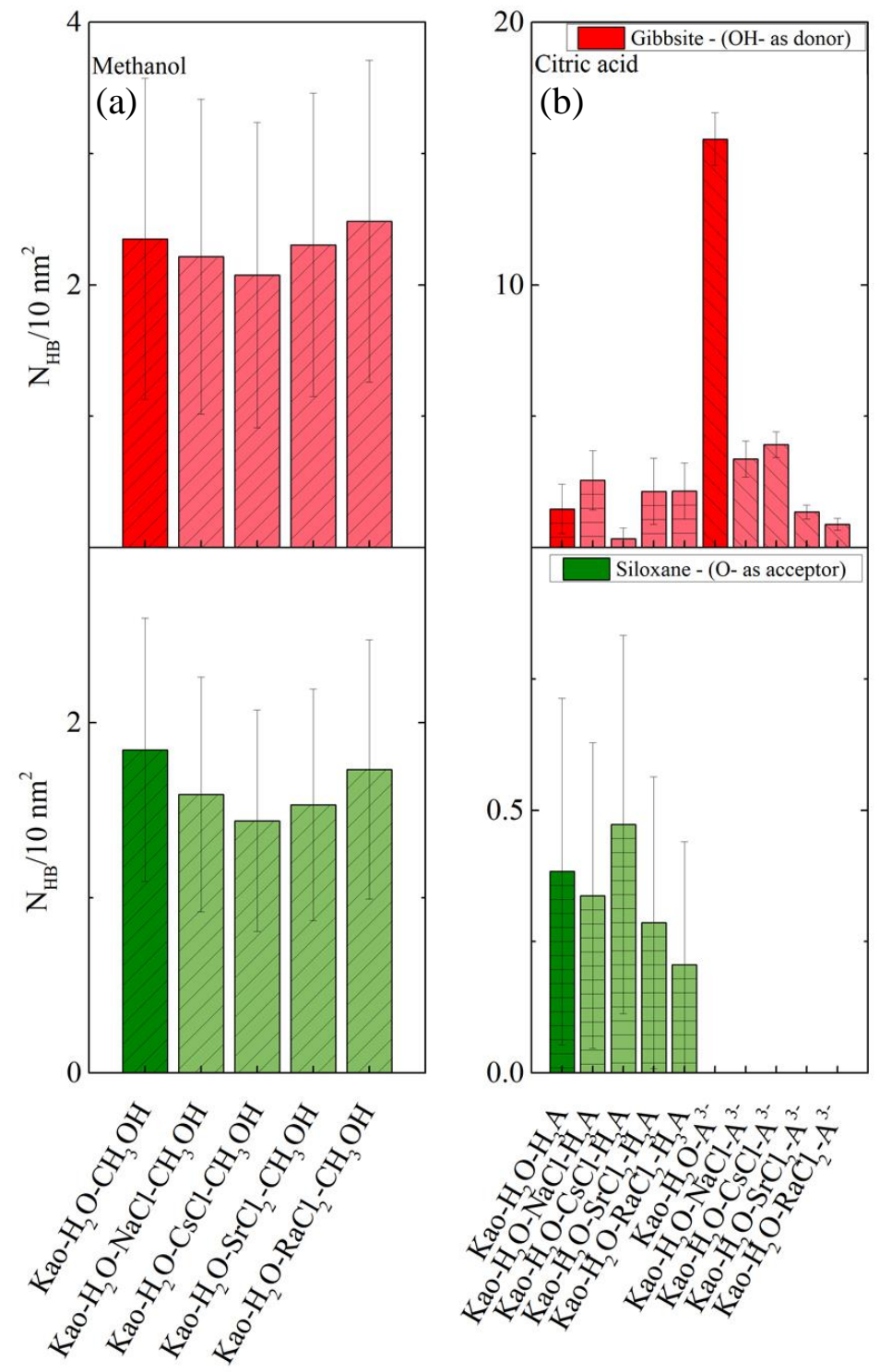

Figure 7. Normalized number of hydrogen bonds, $\mathrm{N}_{\mathrm{HB}}$, between the kaolinite surfaces and a) methanol and b) citric acid. Dark and pale colors illustrate systems without and with salt, respectively. Donor refers to proton donor. 


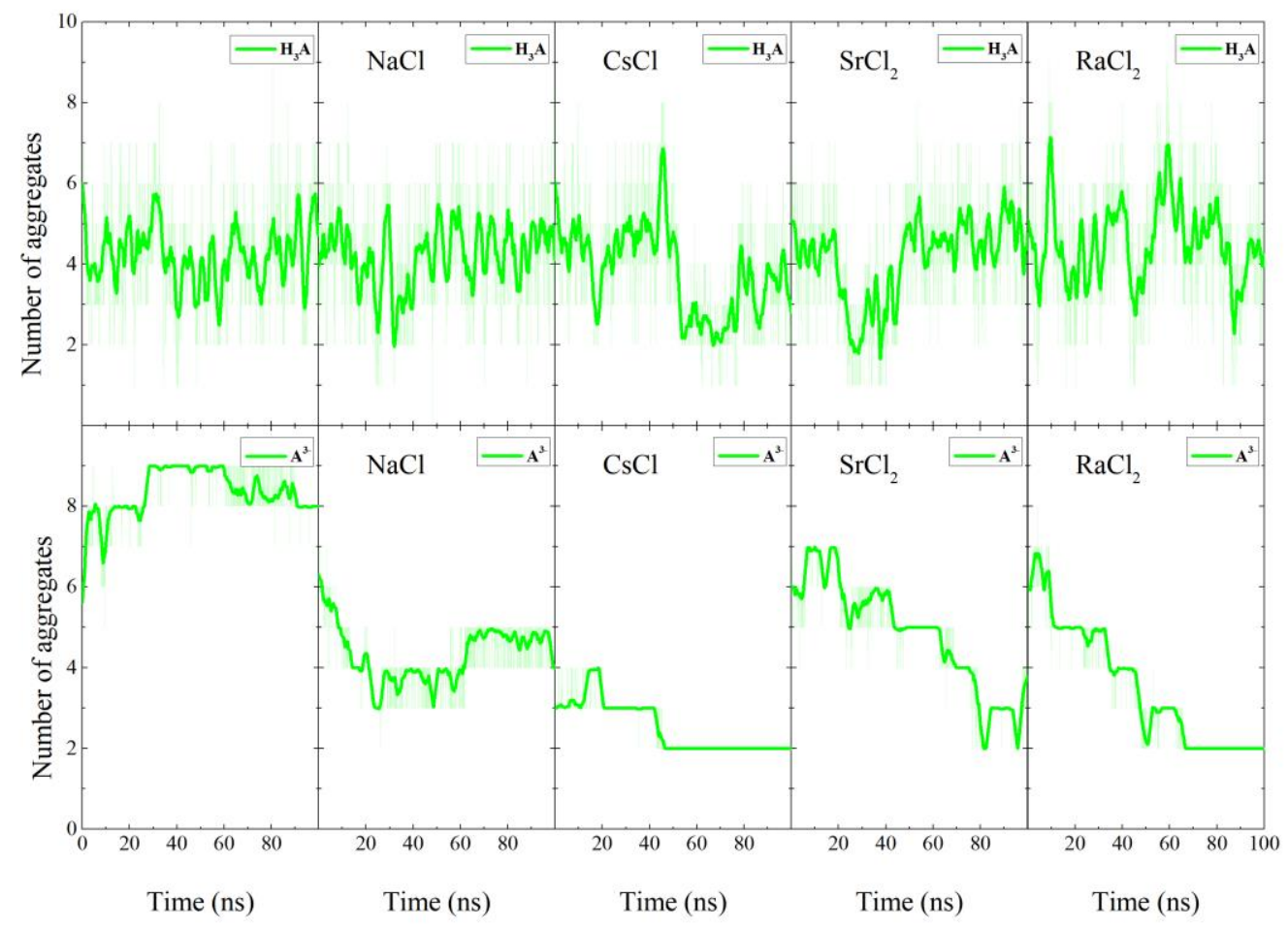

Figure 8. Time evolution of $\mathrm{H}_{3} \mathrm{~A}$ (top) and $\mathrm{A}^{3-}$ (bottom) citric acid number of aggregates in all systems. The thick green line is the running average taken every nanosecond. 


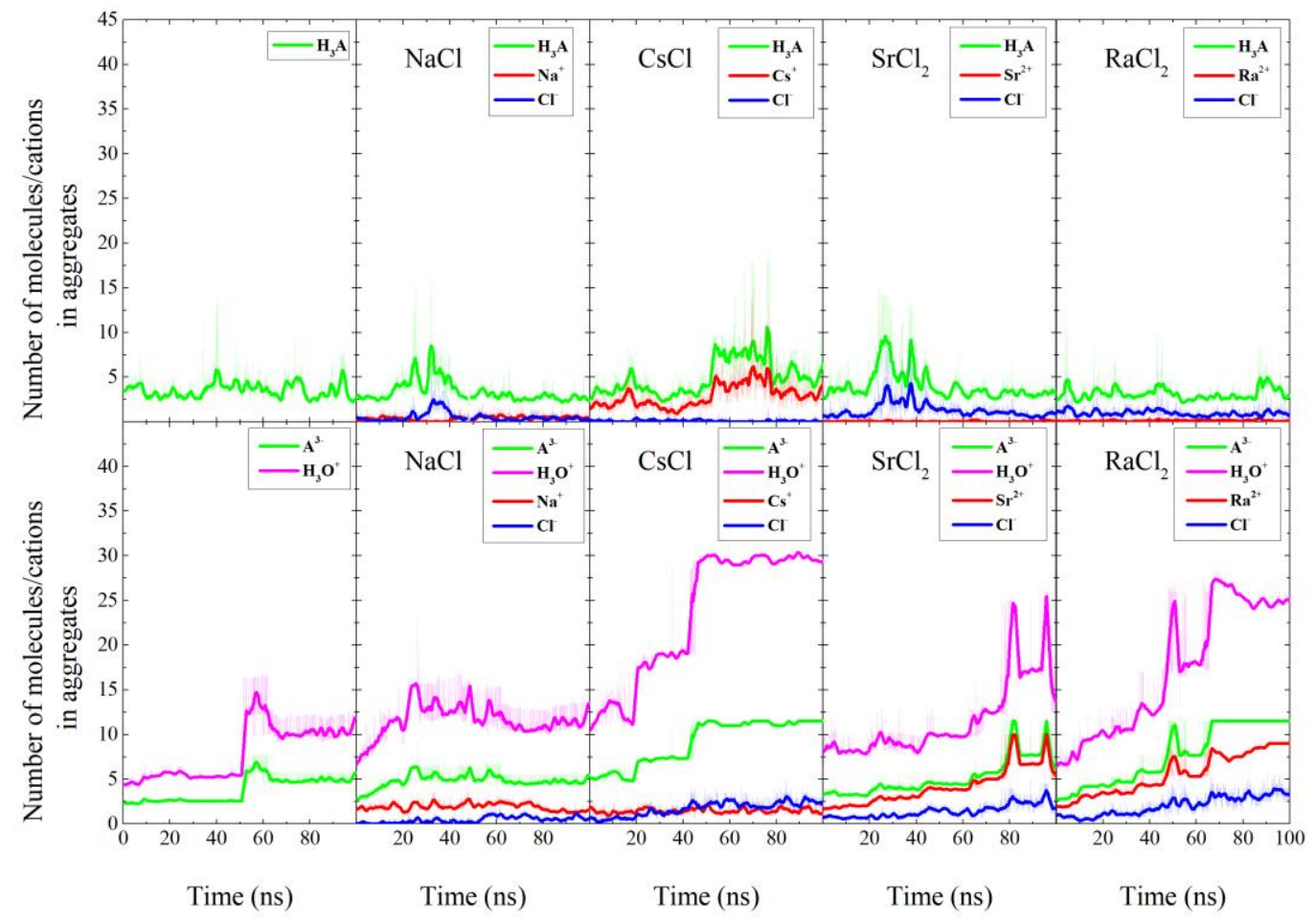

Figure 9. Time evolution of the number of $\mathrm{H}_{3} \mathrm{~A}$ (top) and $\mathrm{A}^{3-}$ (bottom) citric acid molecules, as well as ions participating in aggregates in all systems. The thick lines are the running averages taken every nanosecond. 


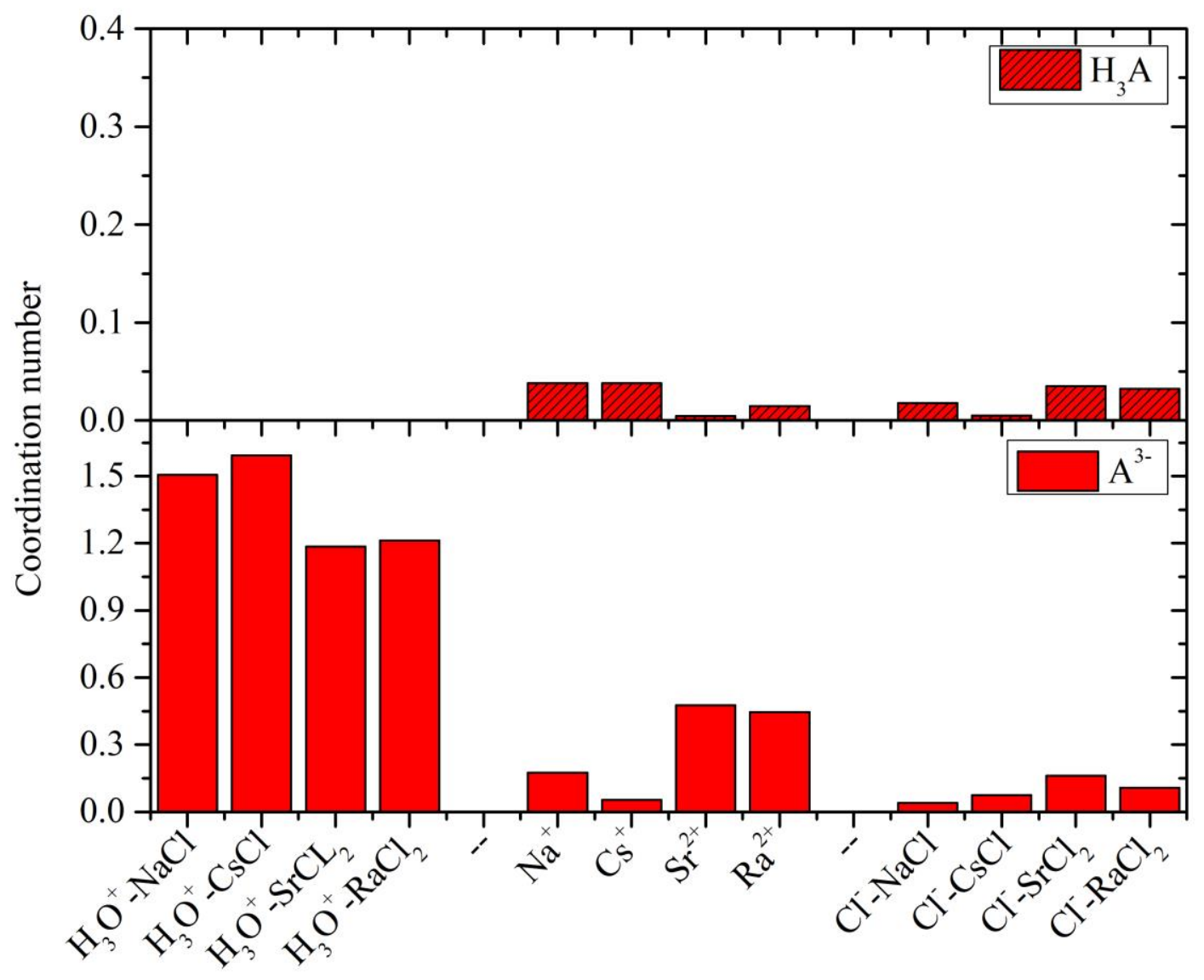

Figure 10. Coordination number of various species with the carboxyl $\left(\mathrm{H}_{3} \mathrm{~A}\right)$ and carboxylate $\left(\mathrm{A}^{3-}\right)$ citric acid oxygens, up to the first minimum of their respective RDFs. 


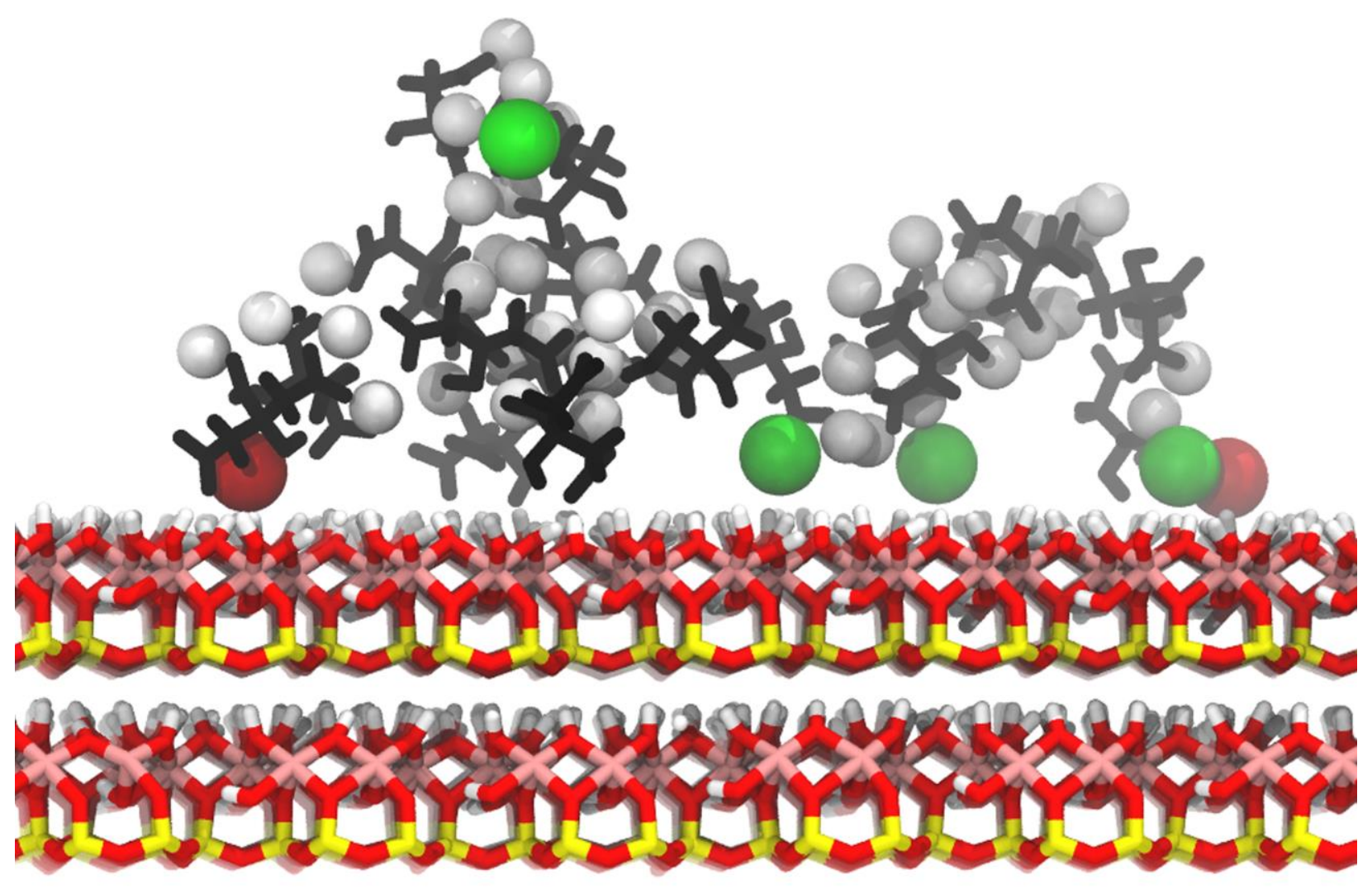

Figure 11. Characteristic snapshot of the $\mathrm{A}^{3-}$ cluster formed in the $\mathrm{CsCl}$ containing system. $\mathrm{A}^{3-}$ molecules (black licorice) are bridged together with $\mathrm{H}_{3} \mathrm{O}^{+}$cations (white spheres) which also interact with $\mathrm{Cl}^{-}$(green spheres) present on the hydroxylated gibbsite surface. The $\mathrm{A}^{3-}$ anchors to the surface through hydrogen bonds and via bridges with $\mathrm{Cs}^{+}$(red spheres). 

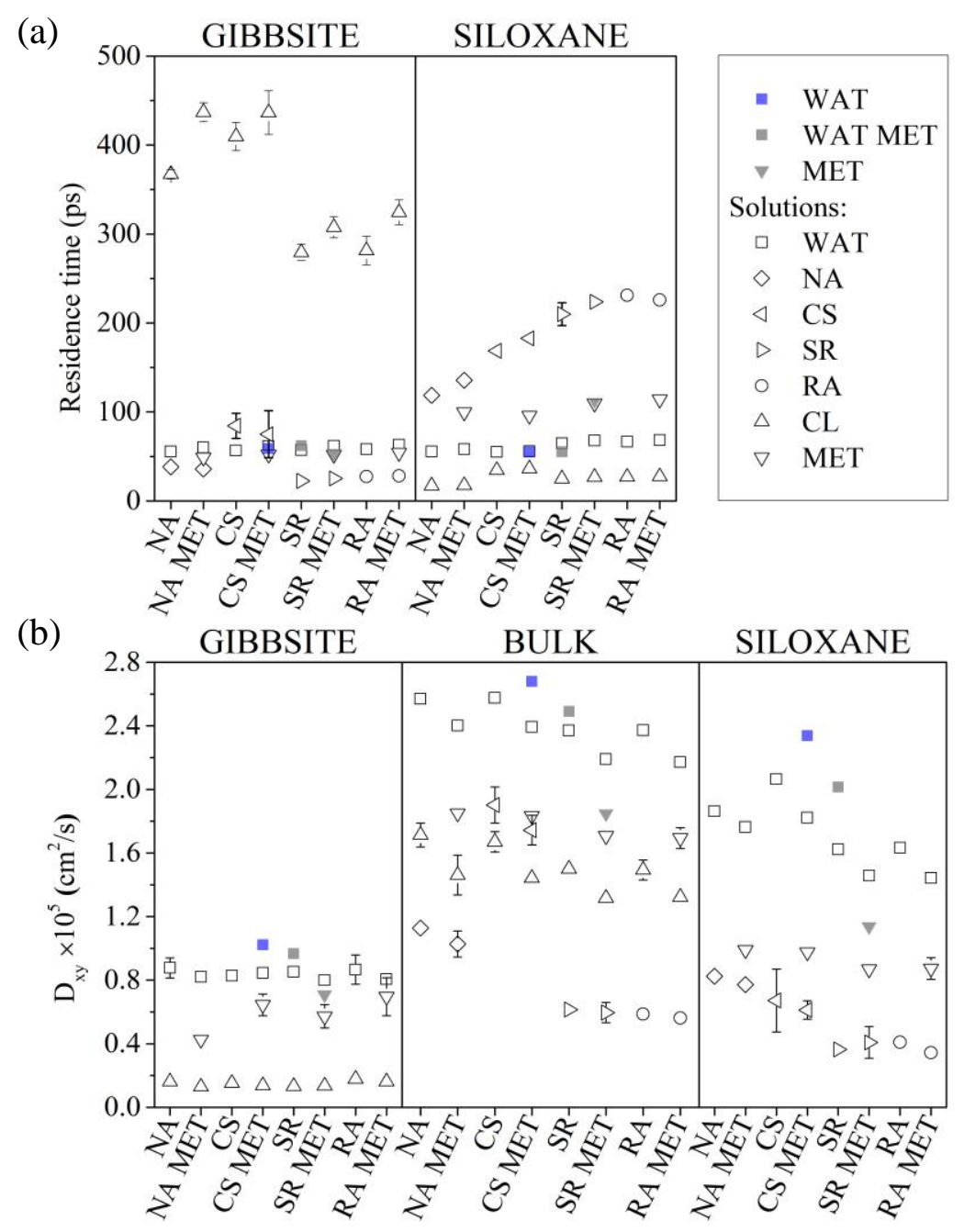

Figure 12. a) Residence times and b) diffusion coefficients for the components of the $0.3 \mathrm{M}$ salt solutions (NA: $\mathrm{NaCl}, \mathrm{CS}: \mathrm{CsCl}, \mathrm{SR}: \mathrm{SrCl}_{2}$ and $\mathrm{RA}: \mathrm{RaCl}_{2}$ ) and the corresponding fluids containing $5 \%$ wt methanol (NA MET, CS MET, SR MET, RA MET). The reported values were calculated based on four blocks where the trajectories of $100 \mathrm{~ns}$ where divided. The same properties for pure water (blue squares) and water (gray squares) with $5 \%$ wt methanol (gray down triangles) solution have also been included for comparison. The values are reported separately for each of the three regions defined along the confinement direction. The diffusion coefficients omitted (cations on the 
gibbsite slab and chloride anion on the siloxane side) are due to the poor statistics of the corresponding species. 


\section{References}

1. Striolo, A.; Cole, D. R. Understanding Shale Gas: Recent Progress and Remaining Challenges. Energy Fuels 2017, 31, 10300-10310.

2. Yethiraj, A.; Striolo, A. Fracking: What Can Physical Chemistry Offer? J. Phys. Chem. Lett. 2013, 4, 687-690.

3. Ghanbari, E.; Dehghanpour, H. Impact of Rock Fabric on Water Imbibition and Salt Diffusion in Gas Shales. Int. J. Coal Geol. 2015, 138, 55-67.

4. Detellier, C.; Letaief, S. Chapter 13.2 - Kaolinite-Polymer Nanocomposites. In Developments in Clay Science, Bergaya, F.; Lagaly, G., Eds. Elsevier: 2013; Vol. 5, pp 707-719.

5. Weaver, C. E. Clays, Muds, and Shales. Elsevier : Distributors for the U.S. and Canada, Elsevier Science Pub. Co.: Amsterdam ; New York, 1989; p 819.

6. Brigatti, M. F.; Galán, E.; Theng, B. K. G. Chapter 2 - Structures and Mineralogy of Clay Minerals. In Developments in Clay Science, 2nd ed.; Bergaya, F.; Theng, B. K. G.; Lagaly, G., Eds. Elsevier: 2006; Vol. 1, pp 19-86.

7. Bish, D. L. Rietveld Refinement of the Kaolinite Structure at 1.5 K. Clay Clay Miner. 1993, 41, 738-744.

8. Miranda-Trevino, J. C.; Coles, C. A. Kaolinite Properties, Structure and Influence of Metal Retention on pH. Appl. Clay Sci. 2003, 23, 133-139.

9. Bhattacharyya, K. G.; Sen Gupta, S. Adsorption of a Few Heavy Metals on Natural and Modified Kaolinite and Montmorillonite: A Review. Adv. Colloid Interface Sci. 2008, 140, 114-131.

10. Mitchell, J. K.; Soga, K. Fundamentals of Soil Behavior. 3rd ed.; John Wiley \& Sons: Hoboken, N.J., 2005; p 577.

11. Deer, W. A.; Howie, R. A.; Zussman, J. An Introduction to the Rock-Forming Minerals. 2nd ed.; John Wiley \& Sons: New York, N.Y., 1992; p 696.

12. McBride, M. B. Copper(II) Interactions with Kaolinite - Factors Controlling Adsorption. Clay Clay Miner. 1978, 26, 101-106.

13. Youell, R. F. Isomorphous Replacement in the Kaolin Group of Minerals. Nature 1958, 181, 557-558.

14. Underwood, T.; Erastova, V.; Greenwell, H. C. Wetting Effects and Molecular Adsorption at Hydrated Kaolinite Clay Mineral Surfaces. J. Phys. Chem. C 2016, 120, 11433-11449.

15. Vasconcelos, I. F.; Bunker, B. A.; Cygan, R. T. Molecular Dynamics Modeling of Ion Adsorption to the Basal Surfaces of Kaolinite. J. Phys. Chem. C 2007, 111, 6753-6762.

16. King, G. E.; Durham, D. Environmental Aspects of Hydraulic Fracturing: What Are the Facts? In Hydraulic Fracturing: Environmental Issues, American Chemical Society: 2015; Vol. 1216, pp 1-44.

17. Speight, J. G. Fracturing Fluids. In Handbook of Hydraulic Fracturing, 1st ed.; John Wiley \& Sons, Inc.: Hoboken, N.J., 2016; pp 165-195.

18. Groundwater Protection Council. Interstate Oil \& Gas Conservation Commission. Fracfocus Chemical Disclosure Registry. https://fracfocus.org/chemical-use/what-chemicals-are-used.

19. Saba, T.; Mohsen, F.; Garry, M.; Murphy, B.; Hilbert, B. White Paper: Methanol Use in Hydraulic Fracturing Fluids; Exponent: Maynard, MA, 2012.

20. Waxman, H. A.; Markey, E. J.; DeGette, D. Chemicals Used in Hydraulic Fracturing; United States House of Representatives, Committee on Energy and Commerce, 2011. States House of Representatives; p 49-88. 
21. Hossaini, M.; Jabs, W.; Grisdale, J. Fracturing with Crosslinked Gelled Methanol - a New Approach to Well Stimulation. J. Can. Pet. Technol. 1989, 28, 49-54.

22. Thompson, J. E.; Mcbain, C.; Gregory, G.; Gerbrandt, D. New Continuous-Mix Process for Gelling Anhydrous Methanol Minimizes Hazards. J. Petrol. Technol. 1992, 44, 832-839.

23. Chen, H.; Carter, K. E. Characterization of the Chemicals Used in Hydraulic Fracturing Fluids for Wells Located in the Marcellus Shale Play. J. Environ. Manage. 2017, 200, 312-324.

24. Jew, A. D.; Dustin, M. K.; Harrison, A. L.; Joe-Wong, C. M.; Thomas, D. L.; Maher, K.; Brown, G. E.; Bargar, J. R. Impact of Organics and Carbonates on the Oxidation and Precipitation of Iron During Hydraulic Fracturing of Shale. Energy Fuels 2017, 31, 3643-3658.

25. Chermak, J. A.; Schreiber, M. E. Mineralogy and Trace Element Geochemistry of Gas Shales in the United States: Environmental Implications. Int. J. Coal Geol. 2014, 126, 32-44.

26. Cheremisinoff, N. P.; Davletshin, A. Management of Chemicals. In Hydraulic Fracturing Operations, John Wiley \& Sons, Inc.: 2015; pp 85-151.

27. Cheremisinoff, N. P.; Davletshin, A. Macro Considerations of Environmental and Public Health Risks. In Hydraulic Fracturing Operations, John Wiley \& Sons, Inc.: 2015; pp 705742.

28. Chapman, E. C.; Capo, R. C.; Stewart, B. W.; Kirby, C. S.; Hammack, R. W.; Schroeder, K. T.; Edenborn, H. M. Geochemical and Strontium Isotope Characterization of Produced Waters from Marcellus Shale Natural Gas Extraction. Environ. Sci. Technol. 2012, 46, 3545-3553.

29. Blauch, M. E.; Myers, R. R.; Moore, T.; Lipinski, B. A.; Houston, N. A. Marcellus Shale PostFrac Flowback Waters - Where Is All the Salt Coming from and What Are the Implications? 2009 Society of Petroleum Engineers Eastern Regional Meeting, SPE 125740, Charleston, WV, 2009; pp 1-20.

30. Kondash, A. J.; Warner, N. R.; Lahav, O.; Vengosh, A. Radium and Barium Removal through Blending Hydraulic Fracturing Fluids with Acid Mine Drainage. Environ. Sci. Technol. 2014, 48, 1334-1342.

31. Argyris, D.; Cole, D. R.; Striolo, A. Ion-Specific Effects under Confinement: The Role of Interfacial Water. Acs Nano 2010, 4, 2035-2042.

32. Ho, T. A.; Argyris, D.; Cole, D. R.; Striolo, A. Aqueous Nacl and Cscl Solutions Confined in Crystalline Slit-Shaped Silica Nanopores of Varying Degree of Protonation. Langmuir 2012, 28, 1256-1266.

33. Greenwell, H. C.; Jones, W.; Coveney, P. V.; Stackhouse, S. On the Application of Computer Simulation Techniques to Anionic and Cationic Clays: A Materials Chemistry Perspective. J. Mater. Chem. 2006, 16, 708-723.

34. Greathouse, J. A.; Johnson, K. L.; Greenwell, H. C. Interaction of Natural Organic Matter with Layered Minerals: Recent Developments in Computational Methods at the Nanoscale. Minerals-Basel 2014, 4, 519-540.

35. Teppen, B. J.; Yu, C. H.; Miller, D. M.; Schafer, L. Molecular Dynamics Simulations of Sorption of Organic Compounds at the Clay Mineral/Aqueous Solution Interface. J. Comput. Chem. 1998, 19, 144-153.

36. Warne, M. R.; Allan, N. L.; Cosgrove, T. Computer Simulation of Water Molecules at Kaolinite and Silica Surfaces. Phys. Chem. Chem. Phys. 2000, 2, 3663-3668.

37. Šolc, R.; Gerzabek, M. H.; Lischka, H.; Tunega, D. Wettability of Kaolinite (001) Surfaces Molecular Dynamic Study. Geoderma 2011, 169, 47-54.

38. Greathouse, J. A.; Geatches, D. L.; Pike, D. Q.; Greenwell, H. C.; Johnston, C. T.; Wilcox, J.; Cygan, R. T. Methylene Blue Adsorption on the Basal Surfaces of Kaolinite: Structure and 
Thermodynamics from Quantum and Classical Molecular Simulation. Clay Clay Miner. 2015, 63, 185-198.

39. Li, X.; Li, H.; Yang, G. Promoting the Adsorption of Metal Ions on Kaolinite by Defect Sites: A Molecular Dynamics Study. Sci. Rep. 2015, 5, 14377.

40. Li, X.; Li, H.; Yang, G. Configuration, Anion-Specific Effects, Diffusion, and Impact on Counterions for Adsorption of Salt Anions at the Interfaces of Clay Minerals. J. Phys. Chem. C 2016, 120, 14621-14630.

41. Zhang, L. H.; Lu, X. C.; Liu, X. D.; Yang, K.; Zhou, H. Q. Surface Wettability of Basal Surfaces of Clay Minerals: Insights from Molecular Dynamics Simulation. Energy Fuel 2016, $30,149-160$.

42. Greathouse, J. A.; Cygan, R. T.; Fredrich, J. T.; Jerauld, G. R. Adsorption of Aqueous Crude Oil Components on the Basal Surfaces of Clay Minerals: Molecular Simulations Including Salinity and Temperature Effects. J. Phys. Chem. C 2017, 121, 22773-22786.

43. Scienomics, Maps Platform, 3.4.2; Paris, France, 2015. http://www.scienomics.com/ (accessed July 28, 2016).

44. Cygan, R. T.; Liang, J. J.; Kalinichev, A. G. Molecular Models of Hydroxide, Oxyhydroxide, and Clay Phases and the Development of a General Force Field. J. Phys. Chem. B 2004, 108, 1255-1266.

45. Ngouana W, B. F.; Kalinichev, A. G. Structural Arrangements of Isomorphic Substitutions in Smectites: Molecular Simulation of the Swelling Properties, Interlayer Structure, and Dynamics of Hydrated Cs-Montmorillonite Revisited with New Clay Models. J. Phys. Chem. C 2014, 118, 12758-12773.

46. Cygan, R. T.; Greathouse, J. A.; Heinz, H.; Kalinichev, A. G. Molecular Models and Simulations of Layered Materials. J. Mater. Chem. 2009, 19, 2470-2481.

47. Berendsen, H. J. C.; Grigera, J. R.; Straatsma, T. P. The Missing Term in Effective Pair Potentials. J. Phys. Chem. 1987, 91, 6269-6271.

48. Moučka, F.; Svoboda, M.; Lísal, M. Modelling Aqueous Solubility of Sodium Chloride in Clays at Thermodynamic Conditions of Hydraulic Fracturing by Molecular Simulations. Phys. Chem. Chem. Phys. 2017, 19, 16586-16599.

49. Becke, A. D. Density-Functional Thermochemistry. III. The Role of Exact Exchange. J. Chem. Phys. 1993, 98, 5648-5652.

50. Stephens, P. J.; Devlin, F. J.; Chabalowski, C. F.; Frisch, M. J. Ab Initio Calculation of Vibrational Absorption and Circular Dichroism Spectra Using Density Functional Force Fields. J. Phys. Chem. 1994, 98, 11623-11627.

51. Hehre, W. J.; Ditchfield, R.; Pople, J. A. Self-Consistent Molecular Orbital Methods. XII. Further Extensions of Gaussian-Type Basis Sets for Use in Molecular Orbital Studies of Organic Molecules. J. Chem. Phys. 1972, 56, 2257-2261.

52. Frisch, M. J.; Trucks, G. W.; Schlegel, H. B.; Scuseria, G. E.; Robb, M. A.; Cheeseman, J. R.; Scalmani, G.; Barone, V.; Mennucci, B.; Petersson, G. A.; Nakatsuji, H.; Caricato, M.; Li, X.; Hratchian, H. P.; Izmaylov, A. F.; Bloino, J.; Zheng, G.; Sonnenberg, J. L.; Hada, M.; Ehara, M.; Toyota, K.; Fukuda, R.; Hasegawa, J.; Ishida, M.; Nakajima, T.; Honda, Y.; Kitao, O.; Nakai, H.; Vreven, T.; Montgomery Jr., J. A.; Peralta, J. E.; Ogliaro, F.; Bearpark, M. J.; Heyd, J.; Brothers, E. N.; Kudin, K. N.; Staroverov, V. N.; Kobayashi, R.; Normand, J.; Raghavachari, K.; Rendell, A. P.; Burant, J. C.; Iyengar, S. S.; Tomasi, J.; Cossi, M.; Rega, N.; Millam, N. J.; Klene, M.; Knox, J. E.; Cross, J. B.; Bakken, V.; Adamo, C.; Jaramillo, J.; Gomperts, R.; Stratmann, R. E.; Yazyev, O.; Austin, A. J.; Cammi, R.; Pomelli, C.; Ochterski, 
J. W.; Martin, R. L.; Morokuma, K.; Zakrzewski, V. G.; Voth, G. A.; Salvador, P.; Dannenberg, J. J.; Dapprich, S.; Daniels, A. D.; Farkas, Ö.; Foresman, J. B.; Ortiz, J. V.; Cioslowski, J.; Fox, D. J., Gaussian 09, Gaussian, Inc.: Wallingford, CT, USA, 2009.

53. Kunze, J.; Burgess, I.; Nichols, R.; Buess-Herman, C.; Lipkowski, J. Electrochemical Evaluation of Citrate Adsorption on $\mathrm{Au}(111)$ and the Stability of Citrate-Reduced Gold Colloids. J. Electroanal. Chem. 2007, 599, 147-159.

54. Besler, B. H.; Merz, K. M.; Kollman, P. A. Atomic Charges Derived from Semiempirical Methods. J. Comput. Chem. 1990, 11, 431-439.

55. Singh, U. C.; Kollman, P. A. An Approach to Computing Electrostatic Charges for Molecules. J. Comput. Chem. 1984, 5, 129-145.

56. Bayly, C. I.; Cieplak, P.; Cornell, W. D.; Kollman, P. A. A Well-Behaved Electrostatic Potential Based Method Using Charge Restraints for Deriving Atomic Charges: The RESP Model. J. Phys. Chem. 1993, 97, 10269-10280.

57. Wang, J. M.; Wang, W.; Kollman, P. A.; Case, D. A. Automatic Atom Type and Bond Type Perception in Molecular Mechanical Calculations. J. Mol. Graph. Model. 2006, 25, 247-260.

58. Case, D. A.; Darden, T. A.; Cheatham, T. E. I.; Simmerling, C. L.; Wang, J.; Duke, R. E.; Luo, R.; Walker, R. C.; Zhang, W.; Merz, K. M.; Roberts, B.; Hayik, S.; Roitberg, A.; Seabra, G.; Swails, J.; Goetz, A. W.; Kolossváry, I.; Wong, K. F.; Paesani, F.; Vanicek, J.; Wolf, R. M.; Liu, J.; Wu, X.; Brozell, S. R.; Steinbrecher, T.; Gohlke, H.; Cai, Q.; Ye, X.; Wang, J.; Hsieh, M.-J.; Cui, G.; Roe, D. R.; Mathews, D. H.; Seetin, M. G.; Salomon-Ferrer, R.; Sagui, C.; Babin, V.; Luchko, T.; Gusarov, S.; Kovalenko, A.; Kollman, P. A., Amber12, University of California: San Francisco, 2012.

59. Wang, J. M.; Wolf, R. M.; Caldwell, J. W.; Kollman, P. A.; Case, D. A. Development and Testing of a General Amber Force Field. J. Comput. Chem. 2004, 25, 1157-1174.

60. Szczerba, M.; Kalinichev, A. G. Intercalation of Ethylene Glycol in Smectites: Several Molecular Simulation Models Verified by X-Ray Diffraction Data. Clay Clay Miner. 2016, 64, 488-502.

61. Shapley, T. V.; Molinari, M.; Zhu, R. L.; Parker, S. C. Atomistic Modeling of the Sorption Free Energy of Dioxins at Clay-Water Interfaces. J. Phys. Chem. C 2013, 117, 24975-24984.

62. Sheng, S. J.; Fu, J.; Wong, B. M.; Wu, J. Z. Solvation Structure of Surface-Supported Amine Fragments: A Molecular Dynamics Study. J. Phys. Chem. C 2017, 121, 22156-22163.

63. Li, P. F.; Song, L. F.; Merz, K. M. Systematic Parameterization of Monovalent Ions Employing the Nonbonded Model. J. Chem. Theory Comput. 2015, 11, 1645-1657.

64. Li, P. F.; Roberts, B. P.; Chakravorty, D. K.; Merz, K. M. Rational Design of Particle Mesh Ewald Compatible Lennard-Jones Parameters for +2 Metal Cations in Explicit Solvent. J. Chem. Theory Comput. 2013, 9, 2733-2748.

65. Lindahl, E.; Hess, B.; van der Spoel, D. GROMACS 3.0: A Package for Molecular Simulation and Trajectory Analysis. J. Mol. Model. 2001, 7, 306-317.

66. Van Der Spoel, D.; Lindahl, E.; Hess, B.; Groenhof, G.; Mark, A. E.; Berendsen, H. J. C. GROMACS: Fast, Flexible, and Free. J. Comput. Chem. 2005, 26, 1701-1718.

67. Berendsen, H. J. C.; van der Spoel, D.; van Drunen, R. GROMACS: A Message-Passing Parallel Molecular Dynamics Implementation. Comput. Phys. Commun. 1995, 91, 43-56.

68. Bekker, H.; Berendsen, H. J. C.; Dijkstra, E. J.; Achterop, S.; Vondrumen, R.; Vanderspoel, D.; Sijbers, A.; Keegstra, H.; Reitsma, B.; Renardus, M. K. R. GROMACS - a Parallel Computer for Molecular-Dynamics Simulations. In 4th International Conference on 
Computational Physics (PC 92), DeGroot, R. A.; Nadrchal, J., Eds. World Scientific Publishing: 1993.

69. Hess, B.; Kutzner, C.; van der Spoel, D.; Lindahl, E. GROMACS 4: Algorithms for Highly Efficient, Load-Balanced, and Scalable Molecular Simulation. J. Chem. Theory Comput. 2008, 4, 435-447.

70. Abraham, M. J.; Murtola, T.; Schulz, R.; Páll, S.; Smith, J. C.; Hess, B.; Lindahl, E. GROMACS: High Performance Molecular Simulations through Multi-Level Parallelism from Laptops to Supercomputers. SoftwareX 2015, 1-2, 19-25.

71. Sousa da Silva, A. W.; Vranken, W. F. ACPYPE - Antechamber Python Parser Interface. BMC Res. Notes 2012, 5, 367-367.

72. Berendsen, H. J. C.; Postma, J. P. M.; van Gunsteren, W. F.; DiNola, A.; Haak, J. R. Molecular Dynamics with Coupling to an External Bath. J. Chem. Phys. 1984, 81, 3684-3690.

73. Hess, B.; Bekker, H.; Berendsen, H. J. C.; Fraaije, J. G. E. M. LINCS: A Linear Constraint Solver for Molecular Simulations. J. Chem. Theory Comput. 1997, 18, 1463-1472.

74. Vega, C.; de Miguel, E. Surface Tension of the Most Popular Models of Water by Using the Test-Area Simulation Method. J. Chem. Phys. 2007, 126, 154707.

75. Darden, T.; York, D.; Pedersen, L. Particle Mesh Ewald: An N.Log(N) Method for Ewald Sums in Large Systems. J. Chem. Phys. 1993, 98, 10089-10092.

76. Salomon-Ferrer, R.; Götz, A. W.; Poole, D.; Le Grand, S.; Walker, R. C. Routine Microsecond Molecular Dynamics Simulations with Amber on GPUs. 2. Explicit Solvent Particle Mesh Ewald. J. Chem. Theory Comput. 2013, 9, 3878-3888.

77. Wennberg, C. L.; Murtola, T.; Hess, B.; Lindahl, E. Lennard-Jones Lattice Summation in Bilayer Simulations Has Critical Effects on Surface Tension and Lipid Properties. J. Chem. Theory Comput. 2013, 9, 3527-3537.

78. Smith, F. T. Atomic Distortion and the Combining Rule for Repulsive Potentials. Phys. Rev. A 1972, 5, 1708-1713.

79. Hoover, W. G. Canonical Dynamics: Equilibrium Phase-Space Distributions. Phys. Rev. A 1985, 31, 1695-1697.

80. Parrinello, M.; Rahman, A. Polymorphic Transitions in Single Crystals: A New Molecular Dynamics Method. J. Appl. Phys. 1981, 52, 7182-7190.

81. Luzar, A.; Chandler, D. Effect of Environment on Hydrogen Bond Dynamics in Liquid Water. Phys. Rev. Lett. 1996, 76, 928-931.

82. Derlacki, Z. J.; Easteal, A. J.; Edge, A. V. J.; Woolf, L. A.; Roksandic, Z. DiffusionCoefficients of Methanol and Water and the Mutual Diffusion-Coefficient in Methanol Water Solutions at $278 \mathrm{~K}$ and 298 K. J. Phys. Chem. 1985, 89, 5318-5322.

83. Braun, B. M.; Weingartner, H. Accurate Self-Diffusion Coefficients of $\mathrm{Li}+, \mathrm{Na}+$, and Cs+ Ions in Aqueous Alkali-Metal Halide Solutions from NMR Spin-Echo Experiments. J. Phys. Chem. 1988, 92, 1342-1346. 